Article

\title{
Practical application of nanotechnology solutions in pavement engineering: Addressing practical road construction related problems using marginal materials stabilised with New-age (Nano) Modified Emulsions (NME) towards sustainable roads
}

\author{
Gerrit J Jordaan ${ }^{1,2, *}$ and Wynand J vdM Steyn ${ }^{3}$ \\ 1 Department of Civil Engineering, University of Pretoria, Pretoria 0002, South Africa \\ 2 Jordaan Professional Services (Pty) Ltd., Pretoria 0062, South Africa \\ 3 School of Engineering and Department of Civil Engineering, University of Pretoria, Pretoria 0002, \\ South Africa; Wynand.steyn@up.ac.za \\ * Correspondence: jordaangj@tshepega.co.za; Tel.: +27-(0)-824164945
}

\begin{abstract}
The use of New-age (Nano) Modified Emulsions (NME) for the stabilisation of marginal materials for use in the upper-pavement layers of roads have been proven in laboratories, through Accelerated Pavement Tests (APT) and in practice. In addition, material design methods have been developed based on the scientific analysis of granular material mineralogy and the chemical interaction with the binder to design a material compatible NME stabilising agent for naturally available (often marginal) materials. However, the introduction of any new disruptive technology in a traditionally well-established industry, such as the road construction industry, is usually associated with considerable resistance. This is especially relevant when the new technology enables the use of granular materials traditionally considered to be of an unacceptable quality in combination with relatively new concepts such as New-age (Nano) Modified Emulsions (NME). In practice, few road construction projects are without any problems. The introduction of new-technologies obviously makes it an easy target to blame for any non-related problem that may arise during construction. This article aims to assist in pre-empting, recognising, preventing and resolving material or non-material related construction problems through the correct identification of the cause of the problem and recommending the best, most cost-effective way to correct any deficiencies on site.
\end{abstract}

Keywords: New-age (Nano) Modified Emulsion (NME) stabilisation; identifying construction problems; preventing construction related problems; material related problems; constructability using nanotechnology applications; nano-silane stabilisation of granular materials; construction quality control problems; construction equipment problems; practical implementation of nano-silane stabilisation. 


\section{Introduction}

Nano-silane products have been used in the built environment in Europe since the 1800 's $[1,2,3]$ for the protection of stone building against the harsh environmental effects, especially with regards to limiting or protection against water damage due to the high rainfall experienced throughout these regions. Many of these buildings are still in everyday use, more than 150 years after first treatment (e.g., the British parliament recommended for treated with silica-ester in 1861 [2]). The same basic concepts developed by trial-and-error in the 1800's by scientists, were used in the modern era (after development of the advanced instruments in the 1980/90's that enabled scientists to manipulate atoms at a nano level, e.g., Atomic Force Microscopes (AFM) [4]), to develop nano-silane products that are now generally used in the built environment in numerous products, including silicon sealants, adhesives and paints.

In the first decade of the $2^{\text {nd }}$ millennium, the potential on nanotechnology applications was recognised in the field of road pavement engineering [5]. Most effort to this regard has been spend on the improvement of the bituminous surfacing, with numerous papers and articles been published over the last decade [6,7]. However, the potential use of available, applicable and proven nanotechnology solutions to enhance and stabilise naturally available materials for use in the base and sub-base layers of roads, received little attention [8]. These materials, in abundance in the developing world, are traditionally considered as marginal of sub-standard or even unsuitable [9] for use in these layers using traditionally test and material characterisation methods for granular materials. It was realised that the successful use of nanotechnology solutions to enable the use of these materials, without compromising the integrity of the pavement structure, could substantially reduce the unit costs of pavement structures [10]. Such developments could be of immense value to assist the developing world to build sustainable road infrastructure required to support economic development.

Over the last few years, the ability of these available nanotechnology solutions to stabilise/enhance/improve naturally available materials has been proven in laboratories $[11,12,13]$, through Accelerated Pavement Testing (APT) $[14,15,16]$ and in practice in southern Africa $[8,17,18]$. In parallel, to move away for the stigma of "snake oils" $[8,10,19]$, scientifically based design methods were developed [19-23] to address any negative connections and engineering concerns. These methods are based on the basic mineralogy $[19,20,23]$ of the naturally available materials and the chemical materials compatibility of the modifying agent $[22,23]$. Adhering to fundamental principles [21], it is ensured that all nano-scale modifications to binders are safe both to the living as well as the environment. Due to the scientific basis of the material design methods, no trial-and-error process of "prove of concept", so familiar in pavement engineering, is required as long as the basic materials design method [23] is followed and the required laboratory tests are performed to optimise designs in terms of fundamental engineering properties [19-23].

The work done on NME stabilising agents, will ensure that engineers can perform scientifically based materials designs for road construction to limit risk and provide sustainable hydrophobic (water repellent) pavement layers with confidence. The general introduction of these nanotechnologies could form the cornerstone of sustainable road networks with proven resistance to the:

- destructive effect of water by introducing the concept of hydrophobicity to every particle within a pavement layer that is being treated and prevent future in-situ chemical decomposition [8];

- Formation of deep-pot-holes when the surfacings has been compromised [23], and

- Destructive effect of over-loading of heavy vehicles with damage factors $[8,15]$ below $\mathrm{n}=2\left(\mathrm{~F}=(\mathrm{P} / 80)^{\mathrm{n}}\right)$.

However, the introduction of any new disruptive technology [24] in a traditionally well-established industry such as the road construction industry, is usually associated with considerable resistance. This is especially relevant when the new technology is based on the: 
- Use of granular materials traditionally considered to be of marginal or even unacceptable quality [9];

- Relatively new concepts in pavement engineering such as New-age (Nano) Modified Emulsions (NME) [8,10];

- Test requirements such as XRD scans [10,4] (relatively old concepts in fields such as geology and mining) to analyse naturally available granular materials [20], and

- Scientifically founded material design methods based on materials mineralogy and material compatible nano-modified stabilising agents $[19,23]$.

Although most of these concepts have been in used for many a decade, if not for more than a century in the built environment [1,2,3], the traditionally road construction industry is notoriously conservative. The benefits in terms of the use of material compatible nanotechnologies to all available construction methods varying from the most basic to the most advanced have been demonstrated [18]. However, it is rare that construction projects are conducted without any problems. In the case of the use of relatively new materials (nanotechnology modifications), this give contractors an obvious scrape-goat to blame, especially in the presence of supervision personnel that are not very experienced.

This article is aimed at pre-empting the "blame" game with examples of typical construction related (equipment and/or procedural) problems and low-risk cost-effective solutions to resolve these problems on site. These examples are actual problems encountered when using anionic NME stabilising agents with marginal materials to construct the base and, in some instances, also the sub-base layers of roads. None of these problems discussed are due to the incorporation of NME stabilising agents. However, in practice, on a construction site, the introduction of any new-technology is based on a concept of "guilty until proved innocent". Hence, the field experience needs to be documented in order to pre-empt and limit opportunities for potential claims.

\section{Design and Investigations Pre-ceding Construction}

The construction of any road should be preceded by the usual design method prescribed by any specific road authority. These design methods and especially the methods of materials investigation may be a function of new road design (e.g. [27]), upgrading and/or rehabilitation of existing surfaced roads (e.g. [28]) or the upgrading of gravel roads (e.g.[29]). With the implementation of nanotechnology solutions for the stabilisation and utilisation of marginal naturally available materials, investigations will include the scientific information required to design material compatible anionic NME stabilising agents [19-23].

It follows, that before construction commenced, available materials in borrow-pits and/or in-situ materials within existing roads (for upgrading or rehabilitation) would have been sampled and tested. The testing, if done according to recommended best practice, will ensure that the data is, accurate, adequate and statistically meaningful [28,31]. Laboratory tests would already have been done to confirm that the available granular materials can successfully be stabilised using NME stabilising agents, meeting the specified requirements of the material classification as per Figure 1 and 2 [23]. The design process will ensure that the probability of the designed material compatible NME stabilising agent be responsible for any construction related problems will be slim if not absent at all. The elimination of this risk is based on the implementation of the basic design requirements $[21,23]$ and the selection of a material compatible NME stabilising agent based on an "end-product specification" $[8,29]$ as recommended. Considering that all basic design procedures and tendering procedures have been fully implemented, any problems experienced during construction will, in all probability, be related to procedural and/or equipment related aspects. 


\begin{tabular}{|c|c|c|c|c|c|}
\hline \multirow[b]{2}{*}{ Test or Indicator } & \multirow[b]{2}{*}{ Material' ${ }^{1}$} & \multicolumn{4}{|c|}{ Material classification } \\
\hline & & NME1 & NME2 & NME3 & NME4 \\
\hline \multicolumn{6}{|c|}{ Minimum material requirements before stabilisation and/or treatment (Natural materials) } \\
\hline \multirow{2}{*}{$\begin{array}{l}\text { Material spec.(minimum) } \\
\text { Unestablished material: } \\
\text { Soaked CBR }{ }^{2}(\%) \\
\text { (Mod AASHTO) }\end{array}$} & \multirow[b]{2}{*}{ NG $/(\mathrm{CS})$} & $>45^{2}(95 \%)$ & \multirow[b]{2}{*}{$\begin{array}{l}>25^{2} \\
(95 \%)\end{array}$} & \multirow[b]{2}{*}{$\begin{array}{l}>10^{2} \\
(93 \%)\end{array}$} & \multirow[b]{2}{*}{$\begin{array}{l}>7^{2} \\
(93 \%)\end{array}$} \\
\hline & & $\mathrm{ACV}<30 \%$ & & & \\
\hline \multirow{2}{*}{ Grading Modulus (GM) } & NG & $>1.8$ & $>1.5$ & - & - \\
\hline & GS & NA & $>1.5$ & - & - \\
\hline Sieve analysis: $\%<0.075 \mathrm{~mm}\left(\mathrm{P}_{0.075}\right)$ & ALL & $<20 \%$ & $<25 \%$ & $<35 \%$ & $<50 \%$ \\
\hline $\begin{array}{l}\text { XRD scans: } \\
\text { - Total sample } \\
-0.075 \mathrm{~mm} \text { fraction }\left(\mathrm{P}_{0.075}\right)\end{array}$ & $\begin{array}{l}\text { ALL } \\
\text { ALL }\end{array}$ & $\begin{array}{l}\sqrt{ } \\
\sqrt{ }\end{array}$ & $\begin{array}{l}\sqrt{ } \\
\sqrt{ }\end{array}$ & $\begin{array}{l}\sqrt{ } \\
\sqrt{ }\end{array}$ & $\begin{array}{l}\sqrt{ } \\
\sqrt{ }\end{array}$ \\
\hline \multirow{6}{*}{$\begin{array}{l}\% \text { Material passing } 2 \mu \mathrm{m}\left(\mathrm{P}_{0.002}\right)(\mathrm{e} . \mathrm{g} \\
\text { Clay \& Mica \& Talc) as a \% of Material } \\
\text { (with Talc }<10 \% \text { ) } \\
\text { (XRD-scans of the material passing } \\
\text { the } 0.075 \mathrm{~mm} \text { sieve is used to } \\
\text { determine the \% clay, mica } \\
\text { (muscovite) and talc in the material - } \\
\text { In this case } \mathrm{P}_{0.002}=\mathrm{P}_{0.075} \times\left(\mathrm{P}_{\text {day. exc in }}\right. \\
\mathrm{P}_{0.075} \text { ) }\end{array}$} & \multicolumn{5}{|c|}{ NME stabilisation with micro-meter $(\mu \mathrm{m})$ emulsion particle sizes } \\
\hline & ALL & $<15 \%$ & $<15 \%$ & $<15 \%$ & $<15 \%$ \\
\hline & \multicolumn{5}{|c|}{$\begin{array}{l}\text { NME stabilisation with emulsion containing micro-scale as well as nano- } \\
\text { scale particles (adjusted according to material grading) }\end{array}$} \\
\hline & ALL & NA & $<35 \%$ & $<35 \%$ & $<35 \%$ \\
\hline & \multicolumn{5}{|c|}{$\begin{array}{c}\text { NME stabilisation with emulsion containing nano-scale and pico-scale } \\
\text { particles (grading adjustments) together with technologies addressing } \\
\text { workability of materials on site }\end{array}$} \\
\hline & ALL & NA & NA & $>35 \%$ & $>35 \%$ \\
\hline \multicolumn{6}{|c|}{ Material specifications after stabilisation and/or treatment } \\
\hline \multirow{2}{*}{$\begin{array}{l}\text { In-situ den sity to be re quired after } \\
\text { stabilisation and compaction (mod } \\
\text { AASHTO) (\%) (minimum) }\end{array}$} & Base & $>100 \%$ & $>100 \%$ & $>98 \%$ & $>97 \%$ \\
\hline & Sub-base & NA & $>98 \%$ & $>97 \%$ & $>95 \%$ \\
\hline $\begin{array}{l}\mathrm{DCP}(\mathrm{DN} \mathrm{mm} / \text { blow)(Quality } \\
\text { control) } \\
\text { (stabilised and compacted) }\end{array}$ & & NA & NA & $<2.6$ & $<3.5$ \\
\hline $\begin{array}{l}\text { Mod AASHTO density (\%) } \\
\text { (for laboratory te sting) }\end{array}$ & & $>100 \%$ & $>100 \%$ & $>100 \%$ & $>100 \%$ \\
\hline \multirow{2}{*}{$\begin{array}{l}{ }^{\star} \mathrm{UCS}_{\text {wet }}(\mathrm{kPa}) \\
(150 \mathrm{~mm} \Phi \text { Sample) }\end{array}$} & Design $^{3}$ & $>2500$ & $>1500$ & $>1000$ & $>750$ \\
\hline & Construction $^{4}$ & $>2200$ & $>1200^{5}$ & $>700^{5}$ & $>450^{5}$ \\
\hline $\begin{array}{l}\text { Retained Compressive Strength } \\
\text { (RCS): (UCSwed UCSdry) (\%) }\end{array}$ & & $>85$ & $>75$ & $>70$ & $>65$ \\
\hline $\begin{array}{l}\text { RCS in relation to minimum } \\
\text { UCS } \\
\left(\operatorname{RCS}_{\text {wet(oriteria }}=\mathrm{RCS}_{\text {efective }}=\right. \\
\left.\left(\mathrm{UCS} \mathrm{S}_{\text {wet }} \mathrm{UCS}_{\text {wetoriteria) }}\right)\right) \\
(\%)\end{array}$ & & $>100$ & $>100$ & $>100$ & $>100$ \\
\hline \multirow{2}{*}{ *|TS wet $_{(\mathrm{kPa})}(150 \mathrm{~mm} Ф$ Sample) } & Design $^{3}$ & $>240$ & $>200$ & $>160$ & $>120$ \\
\hline & Construction $^{4}$ & $>220$ & $>180^{5}$ & $>140^{5}$ & $>100^{5}$ \\
\hline $\begin{array}{l}\text { Retained Tensile strength (RTS): } \\
\text { ITS } \text { I }_{\text {wer }} \text { IT S } S_{d r y}(\%)\end{array}$ & & $>85$ & $>75$ & $>70$ & $>65$ \\
\hline 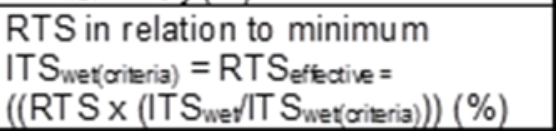 & & $>100$ & $>100$ & $>100$ & $>100$ \\
\hline \multicolumn{6}{|c|}{ 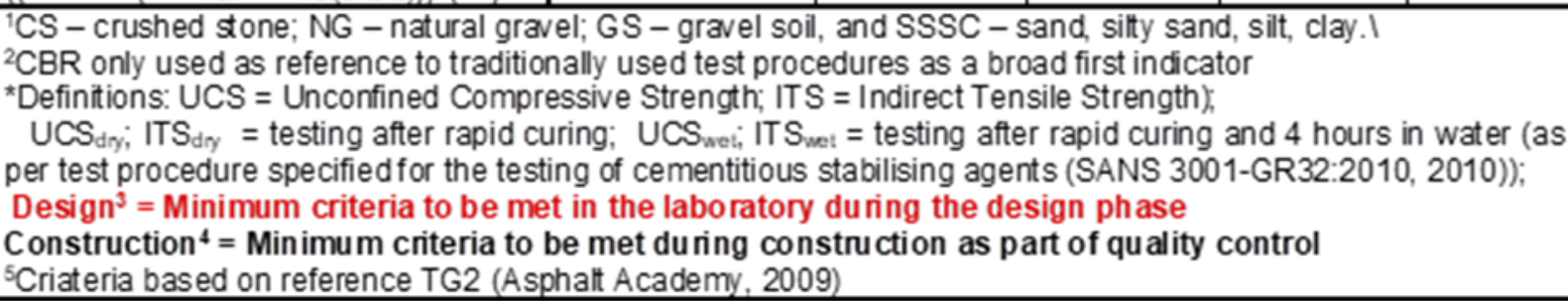 } \\
\hline
\end{tabular}

Figure 1 [23]: Minimum recommended standard specifications for New-age (Nano) Modified (NME) stabilised materials, addressing four different classifications in terms of engineering requirements. 


\begin{tabular}{|c|c|c|c|}
\hline & Material $^{1}$ & \multicolumn{2}{|c|}{$\begin{array}{c}\text { Material clas sification } \\
\text { NME4-Gravel roads } \\
\end{array}$} \\
\hline \multicolumn{4}{|c|}{ Minimum material requirements before stabilisation and/or treatment (Natural materials) } \\
\hline $\begin{array}{l}\text { Material spec.(minimu m) Unstabilised material: } \\
\text { Soaked CBR (\%)(Mod AASHT O) }\end{array}$ & $\begin{array}{l}\text { NG/GS/SSSG } \\
\text { (CS) }\end{array}$ & \multicolumn{2}{|c|}{$>7(93 \%)$} \\
\hline Sieve analysis \% passing the $0.075 \mathrm{~mm}$ sieve $\left(\mathrm{P}_{0.075)}\right.$ & & \multicolumn{2}{|c|}{$<50 \%$} \\
\hline $\begin{array}{l}\text { XRD scans: } \\
\text { - Total sample } \\
-0.075 \mathrm{~mm} \text { fraction }\end{array}$ & $\begin{array}{l}\text { ALL } \\
\text { ALL }\end{array}$ & \multicolumn{2}{|c|}{$\begin{array}{l}\sqrt{ } \\
\sqrt{ }\end{array}$} \\
\hline \multirow{6}{*}{$\begin{array}{l}\text { The greater of: } \\
\text { Identified \% Silt and Clay, or } \\
\% \text { Material passing the } 2 \mu \mathrm{m}(\mathrm{P} 0.002) \text { sieve size (e.g. } \\
\text { Clay \& Mica \& Talc) (with Talc }<10 \%) \text { (XRD-scans of } \\
\text { the material passing the } 0.075 \mathrm{~mm} \text { sieve is } \\
\text { recommended to be used to determine the \% clay, } \\
\text { mica and talc in the material) } \\
\left(\mathrm{P}_{0.075} \times \mathrm{P}_{0.002}\right)\end{array}$} & \multicolumn{3}{|c|}{$\begin{array}{l}\text { NME stabilisation with emulsion particle } \\
\text { size }>2 \mu \mathrm{m}\end{array}$} \\
\hline & ALL & \multicolumn{2}{|c|}{$<15 \%$} \\
\hline & \multicolumn{3}{|c|}{$\begin{array}{c}\text { NME stabilisation with emulsion containing micro- } \\
\text { scale as well as nano-scale particles (adjusted } \\
\text { according to material grading) }\end{array}$} \\
\hline & $\begin{array}{l}\mathrm{ALL} \\
\end{array}$ & $215^{\circ}$ & $35 \%$ \\
\hline & \multicolumn{3}{|c|}{$\begin{array}{c}\text { NME stabilisation with emulsion containing nano- } \\
\text { scale and pico-scale particles (grading adjustments) } \\
\text { together with technologies addressing workability of } \\
\text { materials on site }\end{array}$} \\
\hline & ALL & \multicolumn{2}{|c|}{$>35 \%$} \\
\hline \multicolumn{2}{|c|}{ Material s pecifications after stabilis ation and/or treatment } & NME4 & NME4-WC \\
\hline $\begin{array}{l}\text { In-situ density to be required after stabilisation and } \\
\text { compaction (mod AASHTO) }(\%) \text { (minimum) }\end{array}$ & Base-layer & $>97 \%$ & $>97 \%$ \\
\hline $\begin{array}{l}\text { DCP DN (mm/blow) - (stabilised and compacted) } \\
\text { (Quality control) }\end{array}$ & Top of base & $<3.5$ & $<3.5$ \\
\hline $\begin{array}{l}\text { Mod AASHTO density (\%) } \\
\text { (for labor atory testing) }\end{array}$ & & $>100 \%$ & $>100 \%$ \\
\hline \multirow{2}{*}{ *UCS wat $(\mathrm{kPa})(150 \mathrm{~mm} \Phi$ Sample) } & Design $^{3}$ & $>750$ & $>750$ \\
\hline & Construction $^{4}$ & $>450^{5}$ & $>450^{5}$ \\
\hline 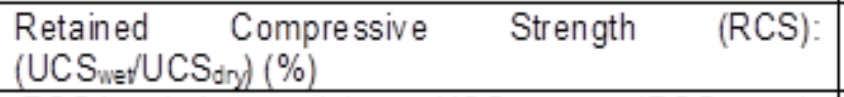 & & $>65$ & $>60$ \\
\hline 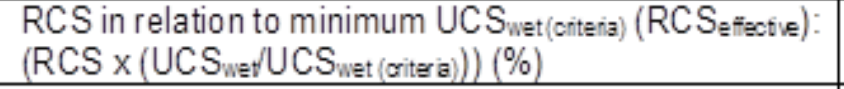 & & $>100$ & $>80$ \\
\hline \multirow{2}{*}{${ }^{*} \mid T S_{\text {wat }}(\mathrm{kPa})(150 \mathrm{~mm} \Phi$ Sample $)$} & Design $^{3}$ & $>120$ & $>70$ \\
\hline & Construction $^{4}$ & $>100^{5}$ & $>50^{6}$ \\
\hline Retained Tensile strength (RTS): ITS & & $>65$ & $>50^{8}$ \\
\hline 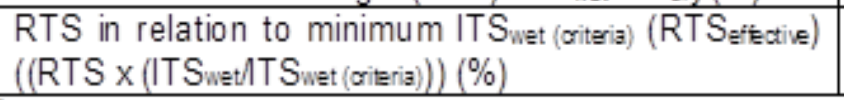 & & $>100$ & $>80$ \\
\hline \multicolumn{4}{|c|}{ 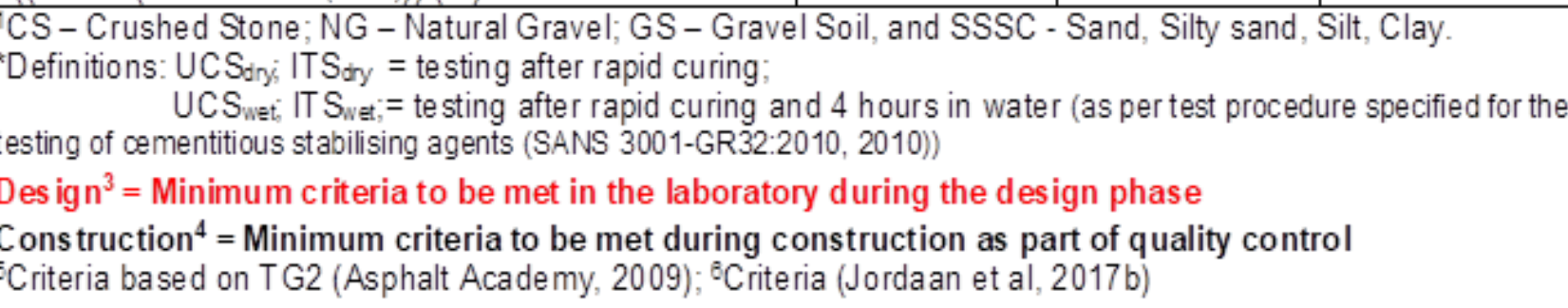 } \\
\hline
\end{tabular}

Figure 2 [29]: Minimum recommended standard specifications for New-age (Nano) Modified (NME) stabilised materials, addressing Low Volume Roads (LVR) and access roads to remote communities and in villages/townships 


\section{Construction of NME Stabilised Granular Pavement Layers - Basic requirements}

\subsection{Construction water quality}

Similar to the construction of any pavement layer, using any stabilising agent, the quality of the construction water must adhere to the requirements generally contained in construction specifications (e.g. $[8,29,30]$. In rural areas this could present some challenges with water often sourced from local streams without any testing of the quality of the water having been performed. Often, water is being pumped without any adequate filter to prevent small particles, etc., being pumped into a water-bowsers. Basic preventative measures implemented in the sourcing of construction water will prevent costly construction problems on site. A good rule of thumb is that the construction water should also qualify for human consumption.

\subsection{Clean equipment}

A pre-requisite to the successful application of a NME stabilising agent is the use of thoroughly cleaned equipment. Although contractors are made aware of this aspect, it is almost without exception, found that the first day of operations present problems with the use of equipment containing residue from previous operations. The organo-functional silane-modification to a stabilising agent is a re-active agent that will react with any bituminous residue left in a water-bowsers, etc. from previous operations. It has become the norm to expect reactions (as shown in Figure 1) questioning the quality of the stabilising agent when the NME stabilising agent is added to uncleaned water-bowsers resulting in the formation of "blobs" or sticky substances (Figure 1(a and b)) of bituminous materials that are unusual. In order to prevent such fist day occurrences, it is recommended that equipment be inspected before being used on site for any NME stabilisation purposes. Figures 1(c and d) show some results of pre-inspections done on "clean" equipment.

\section{Resolving some Common Construction Related Problems experienced during the stabilisation of granular materials using New-age (Nano) Modified Emulsions (NME)}

\subsection{Compaction at moisture conditions of the layer under construction being too low or too high}

Compaction at moisture conditions that are too low are easily recognised in practice, by observing the formation of small cracks appearing behind a smooth-drum roller used for compaction. This aspect is often misdiagnosed on site as signs of "pumping", i.e. too high a moisture content, requiring drying out before final compaction. Such actions will only worsen the situation, basically ensuring that the layer fails in terms of the specified criteria for the layer as per Figures 1 or 2.

A typical example of such cracking is shown in Figure 4. It is always good practice to have a water-bowser on stand-by with a small percentage of diluted anionic NME in construction water. As soon as such cracking is noticed, a light spray with the diluted NME solution, will provide the necessary moisture to compact the layer as a solid unit. The additional NME solution will also enrich the surface of the layer providing additional strength in the top of the layer.

Experience has shown that stabilisation of granular materials using construction water diluted with a material compatible NME stabilising agents are quite resilient and forgiving in nature. In contrast to compaction at too low moisture conditions, the opposite can also happen. It the case of too high moisture conditions, a small "wave" or deformation of material will be noticed to move in front of the smooth drum roller. In such cases, no damage will be done by the ripping of the layer and allowing the material to be exposed to the sun for some of the moisture to evaporate. Recompaction of the layer will have little (if any) impact on engineering strength requirements to be achieved. 


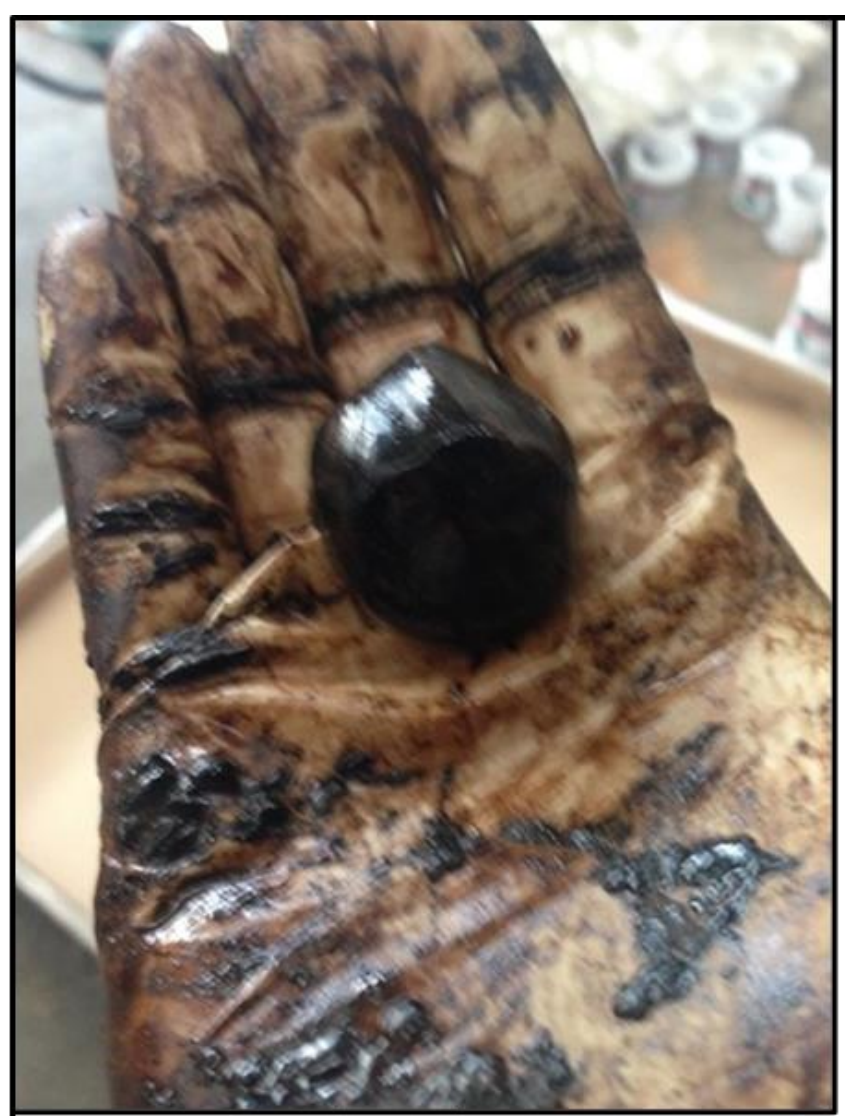

(a)

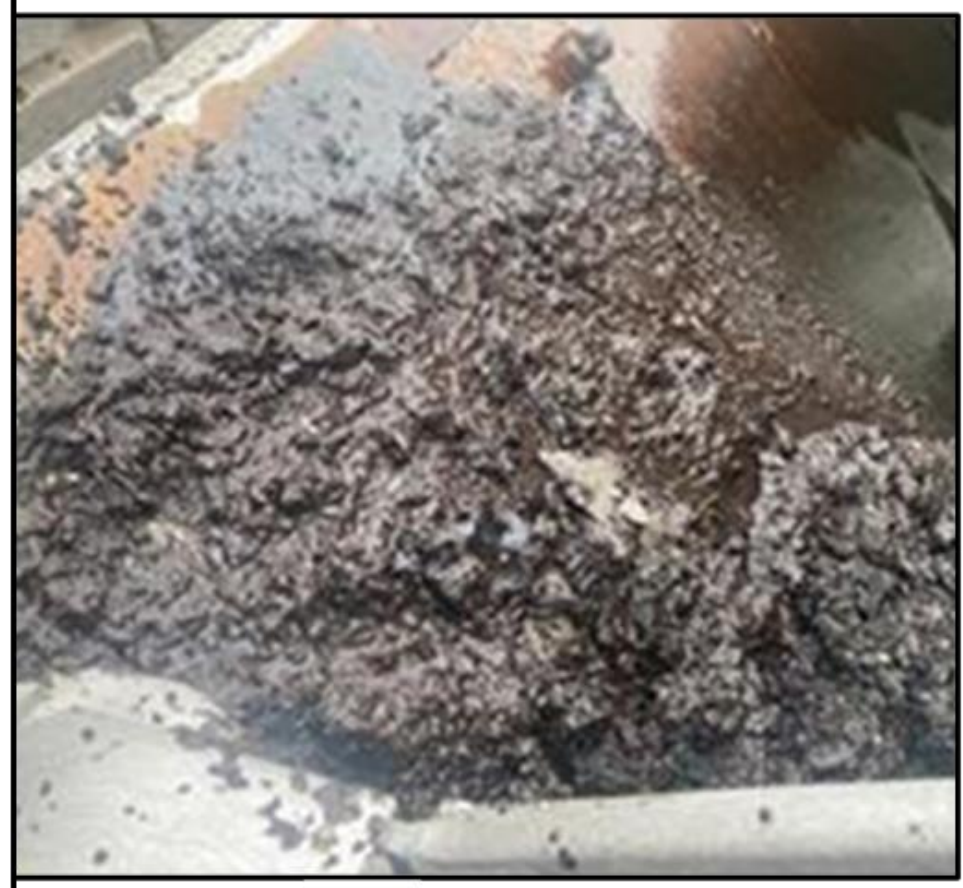

(c)

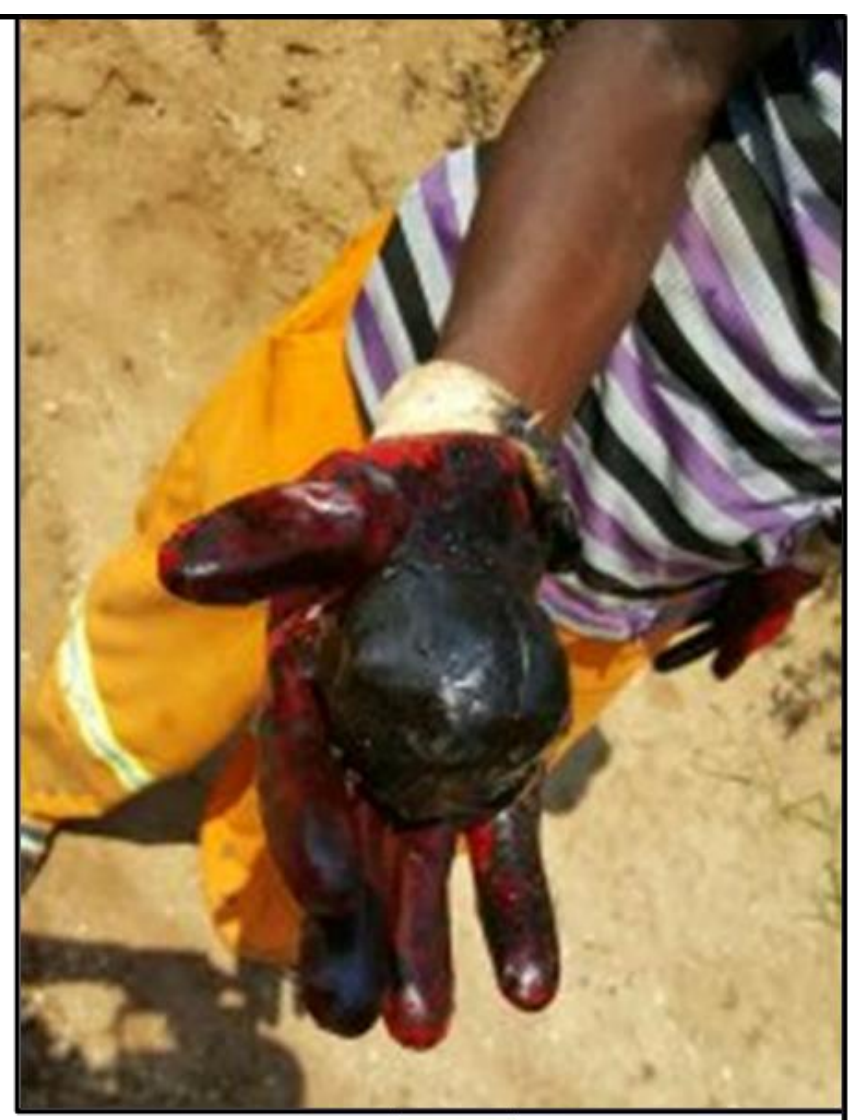

(b)

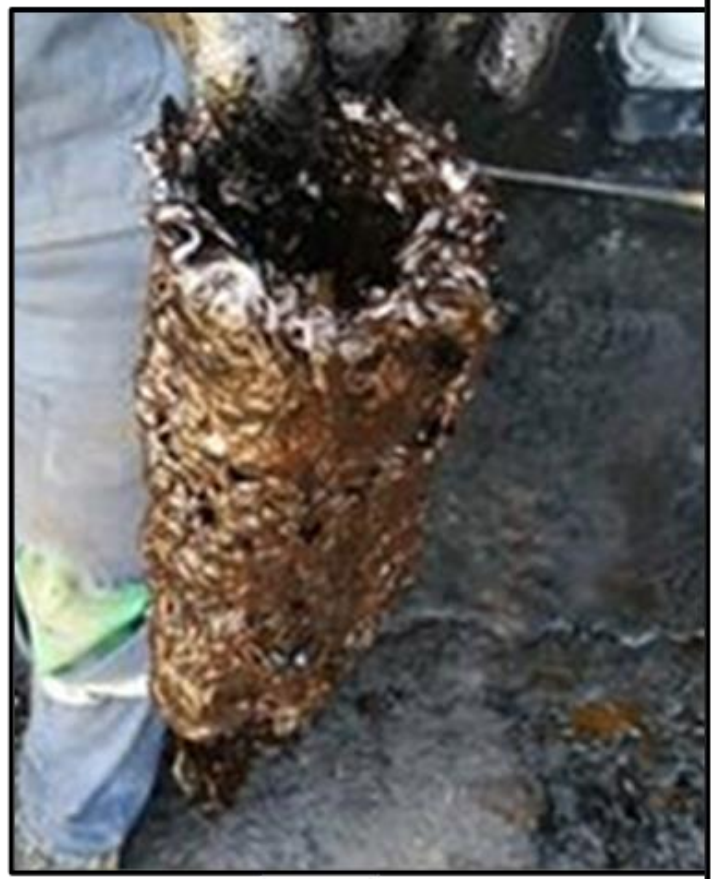

(d)

Figure 3: ( $a$ and b) Typical example of an anionic NME stabilising agent that has been added to the construction waterbowser containing residue from previous operations resulting in a re-action with the residue, resulting in an unusable "blob" of bituminous material; (c and d) Typical examples of residue and state of equipment found during the preinspection of "clean" equipment of contractors for use for the stabilisation of granular materials using an anionic NME. 


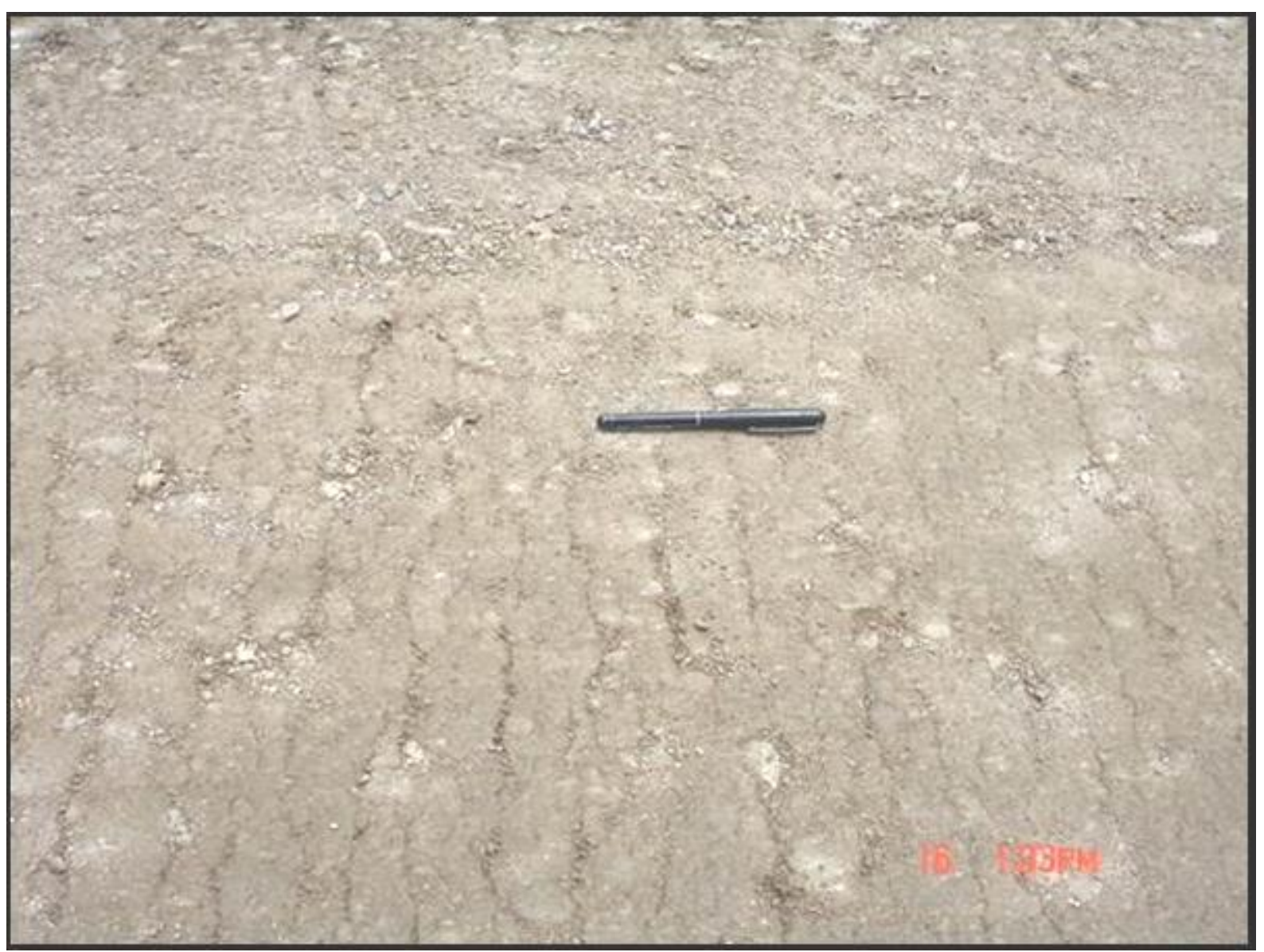

Figure 4: Appearance of small cracks on the surface directly behind a smooth-drum roller which are indicative of moisture conditions in the layer that are too low to achieve good compaction.

In extreme cases, movement of the stabilised layer (even when walking on the layer), after some hours will be an indication of the stabilisation of a pavement layer to the wrong depth (too shallow), resulting in an over application of the stabilising agent. This operational problem is usually associated with inadequate training of operators of the equipment involved, be it with conventional equipment (grader) or a recycler. Opening up of the layer should immediately confirm this aspect.

An extreme example of such an occurrence is shown in Figure 5. Closer investigations have shown that the stabilisation was confined to a depth of $50 \mathrm{~mm}$ only, instead of the specified $150 \mathrm{~mm}$. The depth of stabilisation is the responsibility of the contractor that must ensure that specifications are met. In this case a total rework of the layer to a depth of $150 \mathrm{~mm}$ is the required solution.

Due to the resilient nature of the NME stabilising agent, the reworking can be achieved through the in-situ milling, mixing and windrowing of a $150 \mathrm{~mm}$ of material, followed by the reinstatement of the thoroughly mixed material and re-stabilisation by using 50 per cent of the original specified amount of NME stabilising agent. Care should be taken not to exceed the OMC of the reinstated materials. The organofunctional silane modifying agent (NME) already added to the material will have reduced the original $\mathrm{OMC}$ of the material by at least 10 per cent. Hence, compaction should best be done at a moisture content of about 10 per cent less than the original OMC to avoid movement of the material during decompaction. However, experiences supervision is recommended to ensure that the material is not too dry, exhibiting cracking as shown in Figure 4. 


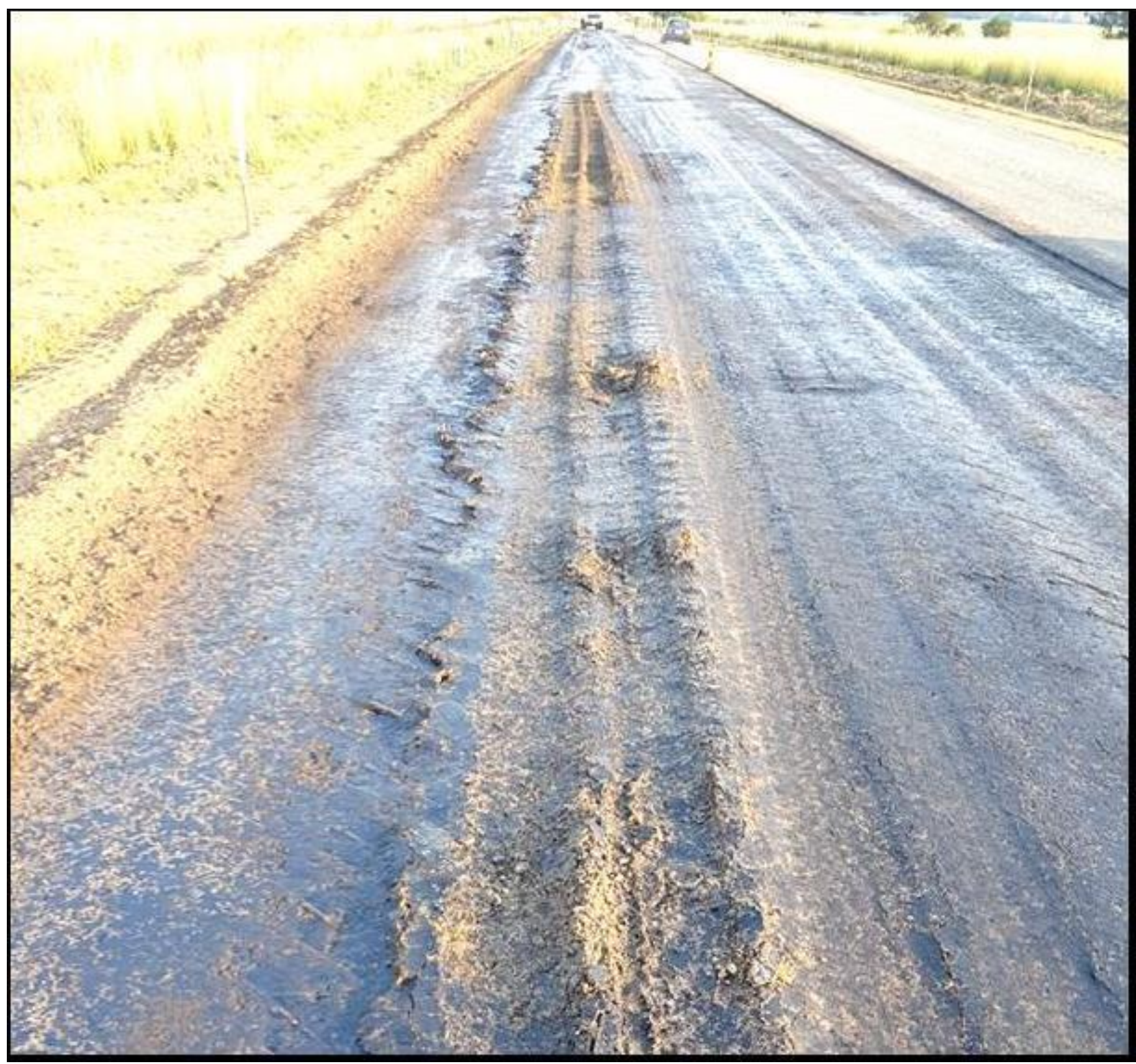

Figure 5: Severe movement of the NME stabilised layer indicative of layer thicknesses not complying to specifications with all the of the NME stabilising agent added to a very thin layer $(50 \mathrm{~mm})$ instead of the specified $150 \mathrm{~mm}$

\subsection{Reworking of layer not meeting criteria and future rehabilitation of NME stabilised layers}

\subsubsection{Reworking of NME stabilised pavement layers}

No construction contract is without any challenges. In all probability some problems will occur resulting in some NME stabilised sections not meeting the specified engineering criteria or, that some equipment failure or problem resulted in a surfacing condition clearly nor meeting requirements, indicating that some problem was experienced during the stabilisation and compaction process. A typical construction equipment related problems are shown in Figures 6 and 7. 


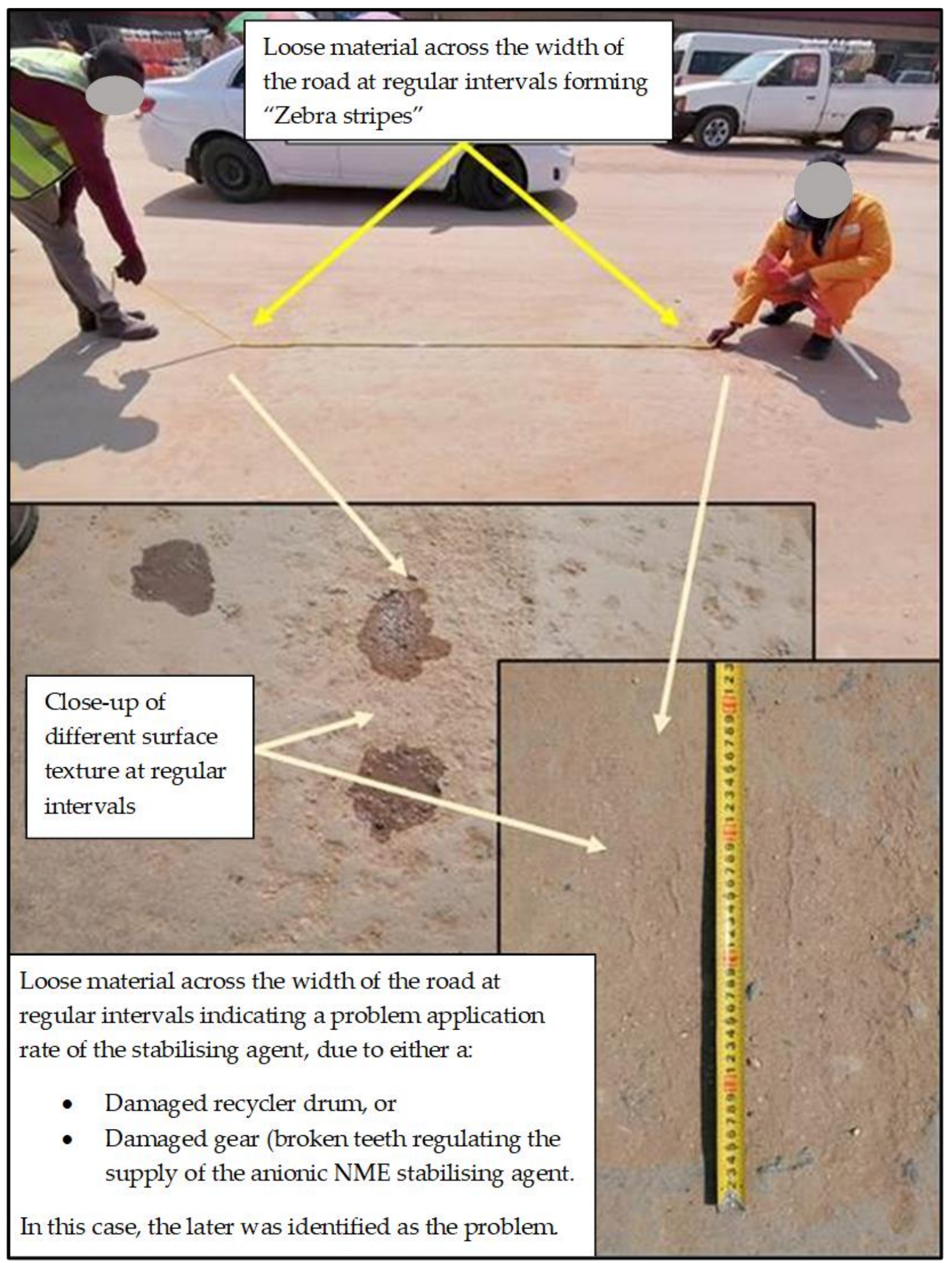

Figure 6: Construction equipment related surfacing problem, showing surface irregularities at regular intervals across the width of the stabilised section stabilised using recycling equipment (these problems are related to the state of the equipment used and independent of the stabilising agent). 


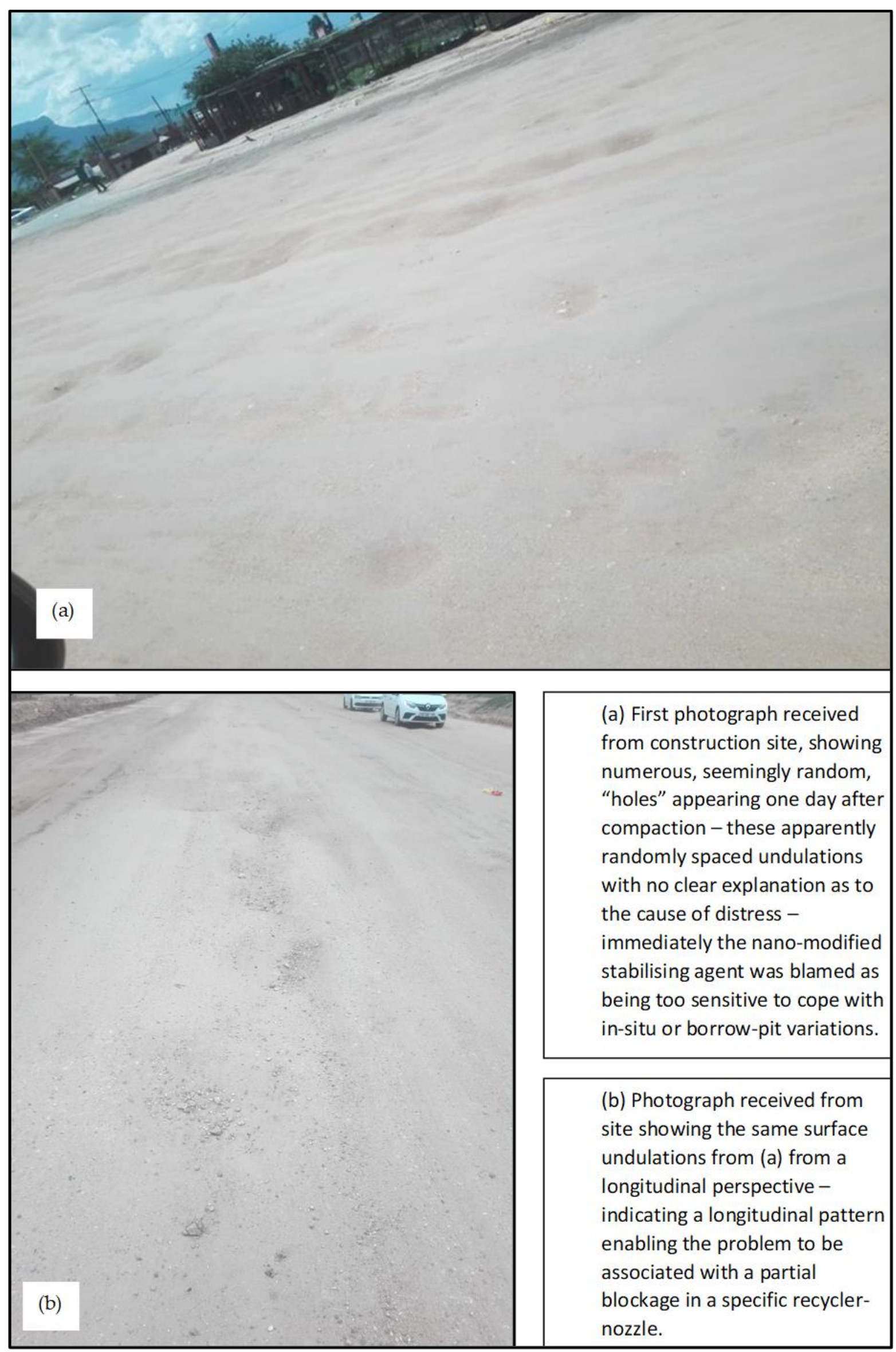

Figure 7: Numerous seemingly random "holes" appearing on the surface the day after stabilisation and compaction. 
The regular intervals of the visible surface irregularities shown in Figure 6, immediately enabled any notion that the problems were associated with the stabilising agent to be discarded. The spacing of the problem seen on the surface indicated that the problem had to be associated with the supply or mixing process, hence a problem associated with the equipment, i.e. in this case, the recycler. Two possible scenarios were identified, i.e. either a drum related problem or a problem associated with the supply of the stabilising agent within the recycler. In this particular case, a broken gear regulating the supply of the diluted NME stabilising agent, resulted in a regular undersupply of the diluted NME stabilising agent which materialised on the pavement layer surface as shown.

The engineering specifications was exceeded by some margin throughout this constructed layer works shown in Figure 6. At his own risk, the contractor reworked the specific section without any addition of stabilising agent or construction water within 24 hours after initial construction. Although a reduction in the original quality control (UCS and ITS) measurements were measured, the reworked road section still met the engineering requirements, the results of which are shown in Table 1. A decrease in the wet UCS and ITS values of less than 20 per cent was measured in this specific project. This example is testimony to the resilient, forgiving nature of the stabilisation of naturally available gravel material (in this case G7 [27] quality material) stabilised with a material compatible NME stabilising agent. It should be emphasized that the dry-remixing of the layer is not the recommended method to rework a layer not meeting the required specifications.

Table 1: Results* of initial stabilisation and dry Reworking of the layer after 24 hours

\begin{tabular}{llll}
\hline & UCS (MPa) & ITS (kPa) & $\begin{array}{l}\text { Material classification } \\
\text { (Construction - Figure 1) }\end{array}$ \\
\hline Construction Specification & 0.70 & 140 & NME3 \\
\hline Initial Stabilisation & 2.95 & 232 & NME1 \\
\hline Dry reworking after 24 hours & 2.40 & 199 & NME2 \\
\hline Loss in strength measurement & $19 \%$ & $14 \%$ & \\
\hline
\end{tabular}

However, the dry-reworking of layers not meeting specifications, or the reworking of NME stabilised pavement layers in future rehabilitation works must be understood in the context of the science behind the anionic NME stabilising agent and the interaction thereof with the granular particles in a pavement layer [19-23]. It is essential to understand that the organofunctional-silane modification of the stabilising agent (anionic NME) enables:

- The ability to cover each particle of the granular material within a pavement layer to become water-repellent (hydrophobic) (provided a scientifically based design procedure is followed $[8,23])$; and

- To provide a strong chemical bond between the granular particles and the stabilising agent (i.e. bitumen emulsion or equivalent polymer).

Should a layer need to be reworked for whatever reason, the weakest link will be broken, which most probable will either be the bitumen stabilising agent (especially when it is relatively freshly stabilised) or, in the case of severely weathered materials, the granular particles itself will break. In the example shown in Figure 6 and Table 1, the primary minerals measured contained a high percentage of silicon in the form of quarzitic material that are relatively hard. These material particles did not break during reworking of the layer with the recycler. The strong chemical bonds between the primary minerals and the nano-silane were also not broken. Hence, the bitumen stabilising agent (still relatively fresh and viscous) sheared during reworking and then bound together again during recompacting to generate adequate in-situ strength properties as confirmed by the test results. Off-cause not all bonds could be recreated, resulting in the measured reduction in UCS and ITS measurements as shown in Table 1. 
The identification of the problem shown in Figure 7 was somewhat more difficult to identify due to the seemingly randomness of the "holes" that became visible on the surface the day after construction as shown in Figure 7(a). However, in a longitudinal direction (Figure 7(b)) some pattern could be identified, pointing to an irregular supply of the stabilising agent associated with a specific nozzle. After inspection a small stone was found in nozzle No. 6 in the recycler (this stone was most likely picked up with the construction water in a local stream with no filter attached to the pipe used to source the construction water.

It could happen that during construction, design specifications are initially not met for whatever reason e.g., compaction at moisture conditions either too low or too high (this is normally the case within most problems experienced on site) or breakage of construction equipment during the construction process. Experience has shown that the insitu reworking of such layers with the addition of 50 per cent of the initial specified anionic NME stabilising agent, will ensure that the reworked layer will easily surpass the required specification (i.e. if the initial design required stabilisation of the granular materials was found to be 0.7 per cent anionic NME, reworking with 0.35 per cent anionic NME (approximately 0.2 per cent residual bitumen), will suffice for the reworking of the layer in order to meet the engineering specifications). In these cases the construction water together with the additional anionic NME stabilising agent will be considerably less than the initial required construction water. The water will now only be used as a distribution agent of the stabilising agent and act as a lubricant during construction. Little (if some aggregate brakeage occurs during the remixing) or no absorption of the water by the aggregate (granular particles) will occur and the layer will become dry at a much-accelerated rate.

This characteristics are demonstrated in Figure 8 [13],showing the change in the characteristics of dolomite material tested before and after stabilisation with a material compatible NME stabilising agent (in this case the material compatible NME required a Hydroxy Conversion Treatment (HCT) [20,23], because of the lack of silicon in dolomite). It is seen that the density versus moisture content becomes less sensitive to changes in the compaction moisture content as a function of OMC. Hence, the required specified density could be achieved at lower moisture conditions. This aspect could be a significant factor for the construction of roads where construction water may be a scarcity. Should the layer require reworking due to any problems (e.g. as shown in Figure 6 or 7), and the design criteria was exceeded by some considerable margin, dry reworking as shown in Table 1 , could be a viable option, depending on the quality and percentage of the primary mineral present in the granular layer as explained. However, such actions will be done solely at the risk of the contractor and is not the recommended procedure for remixing.

\subsubsection{Concerns with regard to the future rehabilitation}

Future rehabilitation of pavement layers originally stabilised with a water-repellent NME stabilising agent will be exactly the same as discussed in the previous section. It should be realised that the material particles are rendered hydrophobic and that the stabilising agent is still an organic substance (bitumen or equivalent polymer of similar characteristics). The only change will be in the amount of water required to recompact or restabilise a previously stabilised granular layer using a NME stabilising agent - similar to the graph shown in Figure 8. Less water will be required to achieve the specified density - a considerable advantage in water-challenged regions of the world. With predictions of climate change and earth warming this factor could become more significant in future road construction projects and towards more sustainable construction materials and methods. 


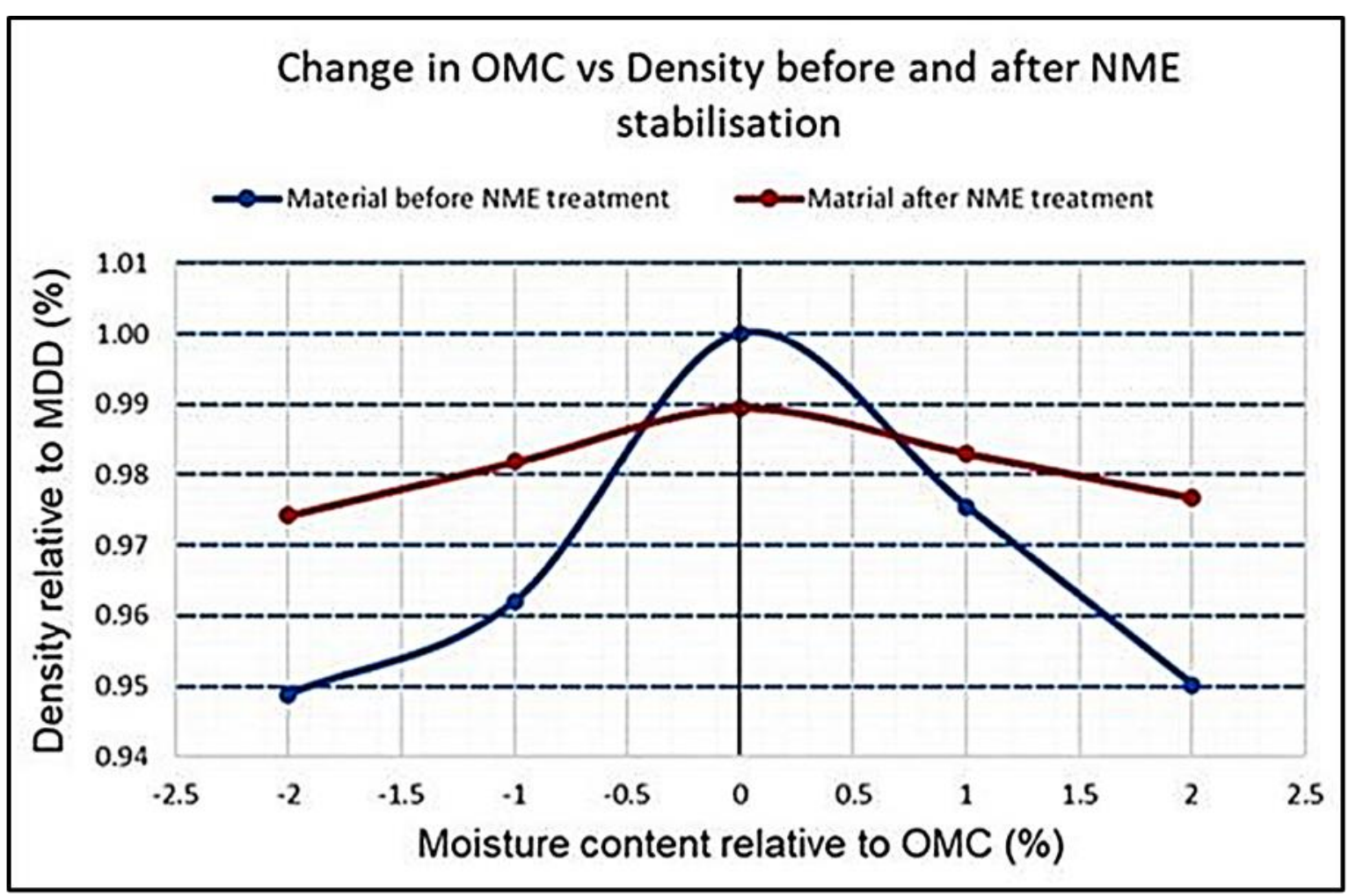

Figure 8: Change in material relative density as a function in the change of moisture relative to the OMC before (dark blue) and after (red) stabilisation using a material compatible anionic NME stabilising agent..

\subsection{Uneven spray rates caused by blocked nozzles noticed during construction using recyclers}

It is essential that construction be done with sufficient experienced personnel. Figure 9 shows the typical visual appearance of a granular layer that has just been mixed with the NME stabilising agent diluted within the construction water. In the case of any blocked nozzles, resulting in the uneven distribution of the stabilising agent within the construction water as shown in Figure 10, the problem should be immediately detected (provided experienced supervisory personnel are on site), and rectified with little additional costs and effort. Blocked nozzles are a common problem often related to poorly cleaned and or maintained equipment.

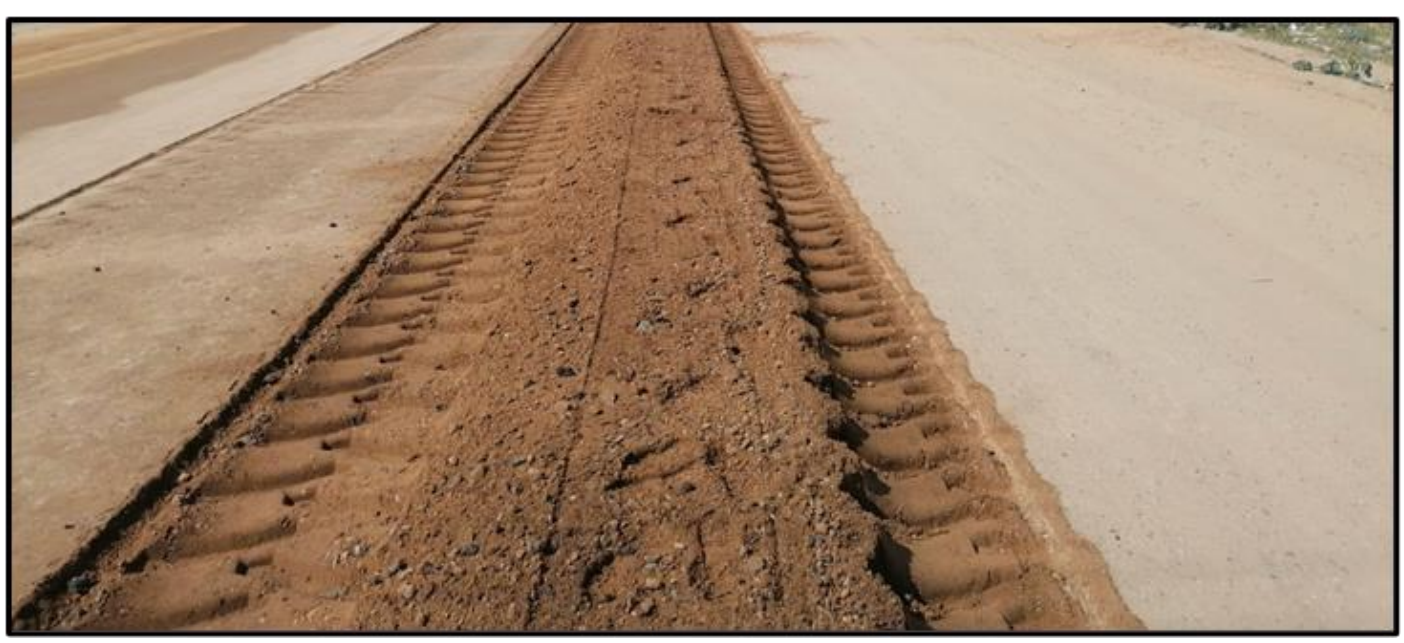

Figure 9: Uniform visual appearance of a uniform mix of the granular material with the anionic NME stabilising agent within the construction water. 


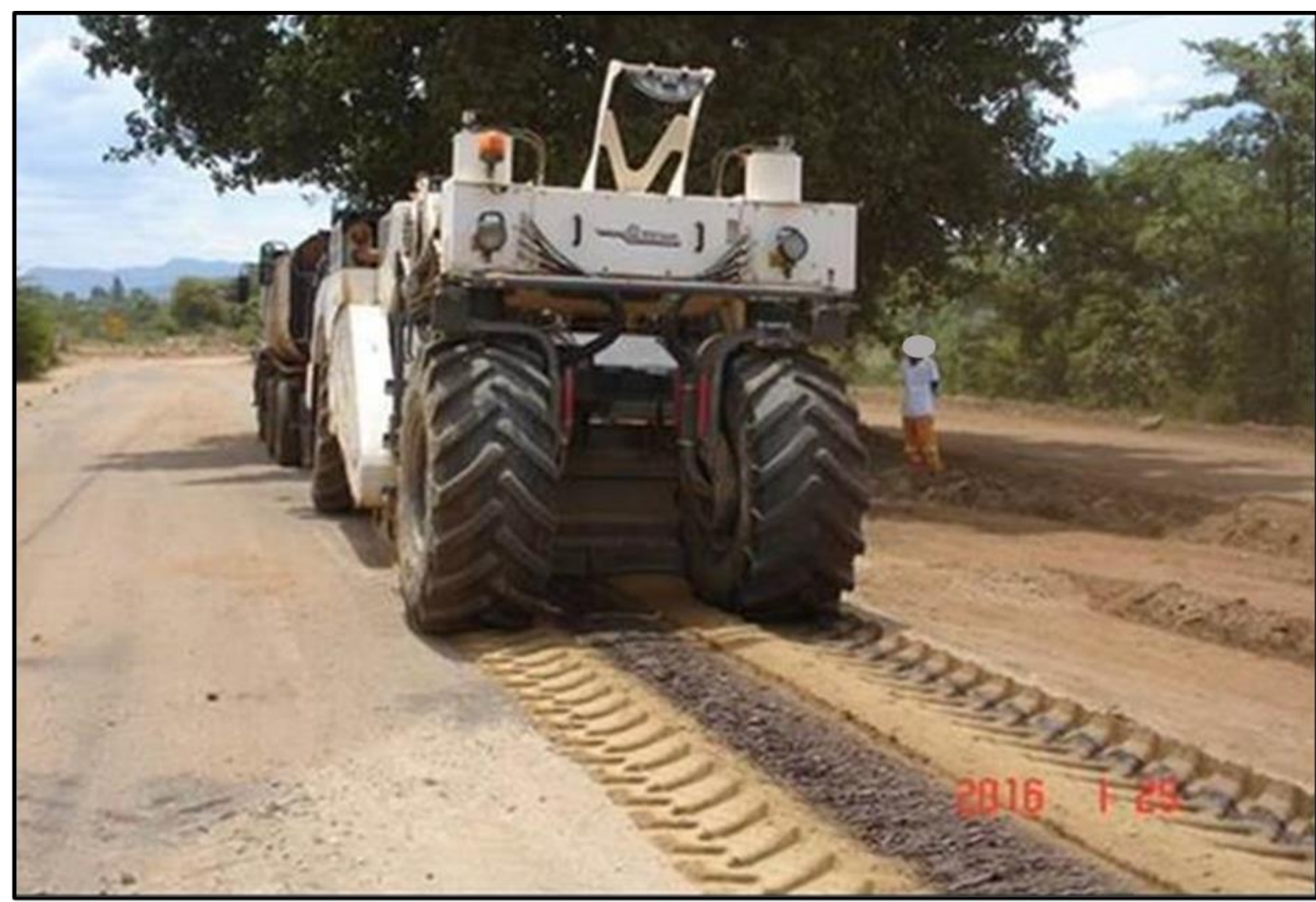

Figure 10: Uneven distribution of the anionic NME stabilising agent within the construction water behind the recycler caused by blocked spray-nozzles

The NME stabilising agent need to be evenly distributed through the width and depth of any layer during construction to achieve the required engineering properties, similarly to any other stabilising agent. Due to the resilient nature of the NME stabilising agent as discussed in the preceding sections, this particular problem (Figure 10) can be resolved easily using conventional equipment to evenly distribute and mix the stabilising agent into the layer as demonstrated in Figures 11.

\subsection{Post-construction problems blamed on the "nano"-stabilised base layer}

In this particular case, severe rut-depth in excess of $50 \mathrm{~mm}$ (Figure 12(a)) crocodile cracking, pot-holes and general failed conditions (Figure 12(b)) were detected at the end of the construction break over the summer holidays on a section of road, constructed just before the summer break. The pavement consisted of a $35 \mathrm{~mm}$ asphalt surfacing with a $150 \mathrm{~mm}$ base-layer stabilised with an anionic NME stabilised granular (G7 [27] quality) material. It was immediately argued that the extend of the damage must be related to the "nano" stabilised based layer.

A forensic investigation was required to determine the actual case and mechanism of distress - the evidence of which could clearly be seen on site by an experienced engineer and a simple investigation of construction records. An on-site investigation showed that the "crocodile" cracking actually started as parabolic cracking indicative of shear during compaction. Similarly, pot-holes still contained the primed sections still attached to the exposed base, indicating that the asphalt surfacing sheared off from the primed base with few pot-holes exceeding the depth of the surfacing as shown in Figure 13. 


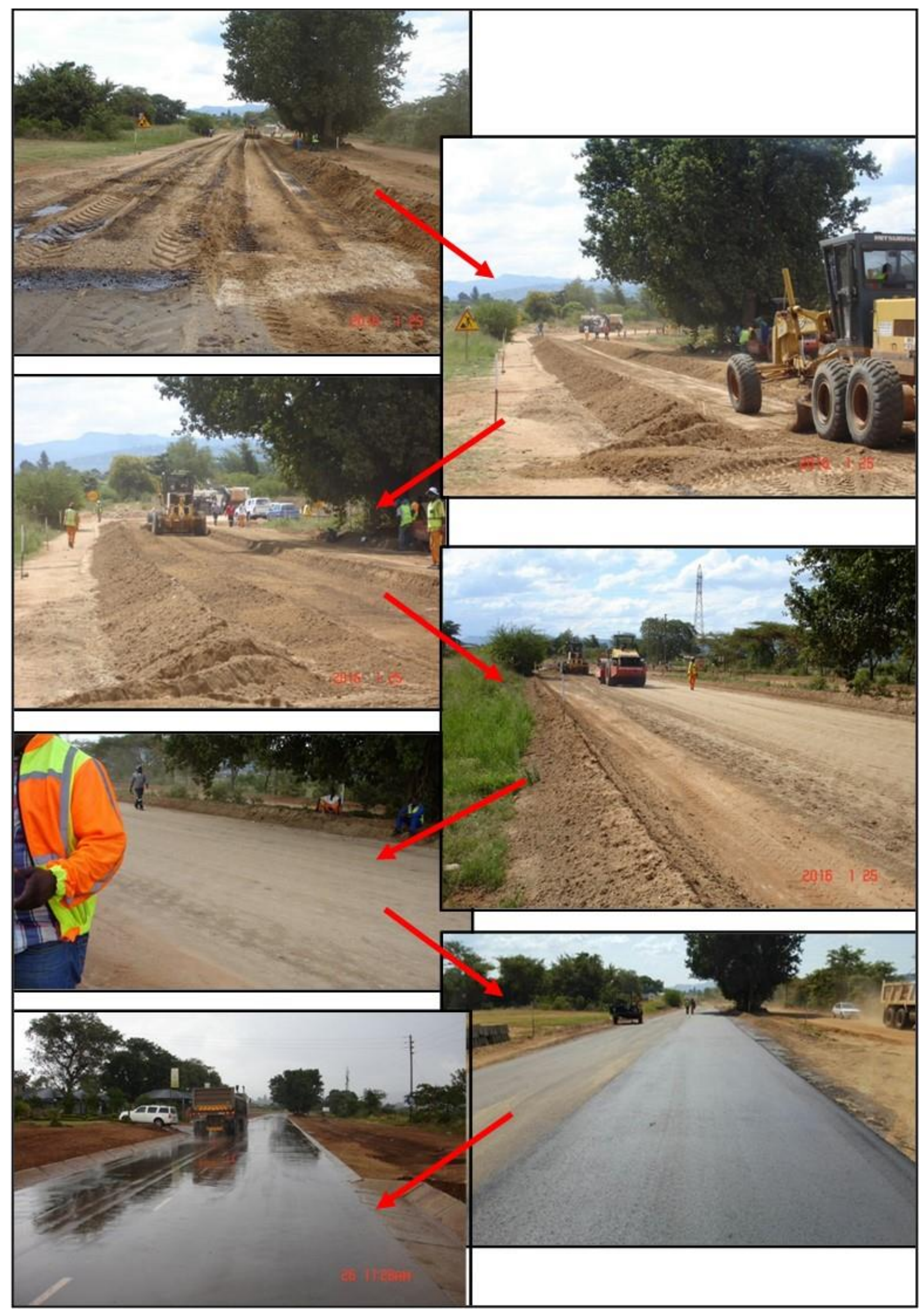

Figure 11: Resolving the uneven distribution of the NME stabilising agent trough the remixing of the road pavement layer using conventional equipment. 


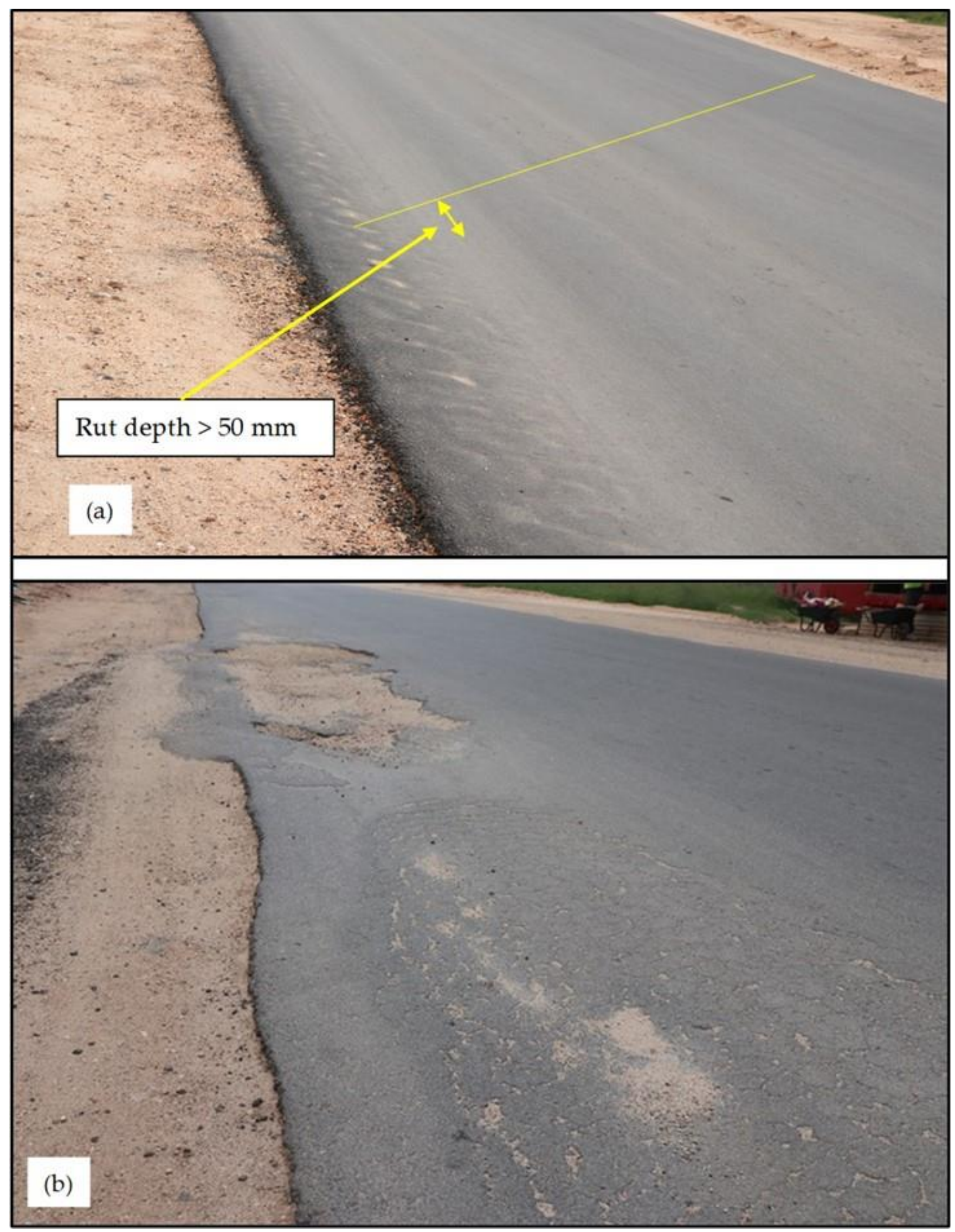

Figure 12: Pavement section with $35 \mathrm{~mm}$ asphalt surfacing and a $150 \mathrm{~mm}$ anionic NME stabilised base layer. Condition of completed section of road one month after the summer break, with (a) rut-depth in wheel-tracks exceeding 50 mm and (b) severe distress with crocodile cracking, pot-holes and general failures. 

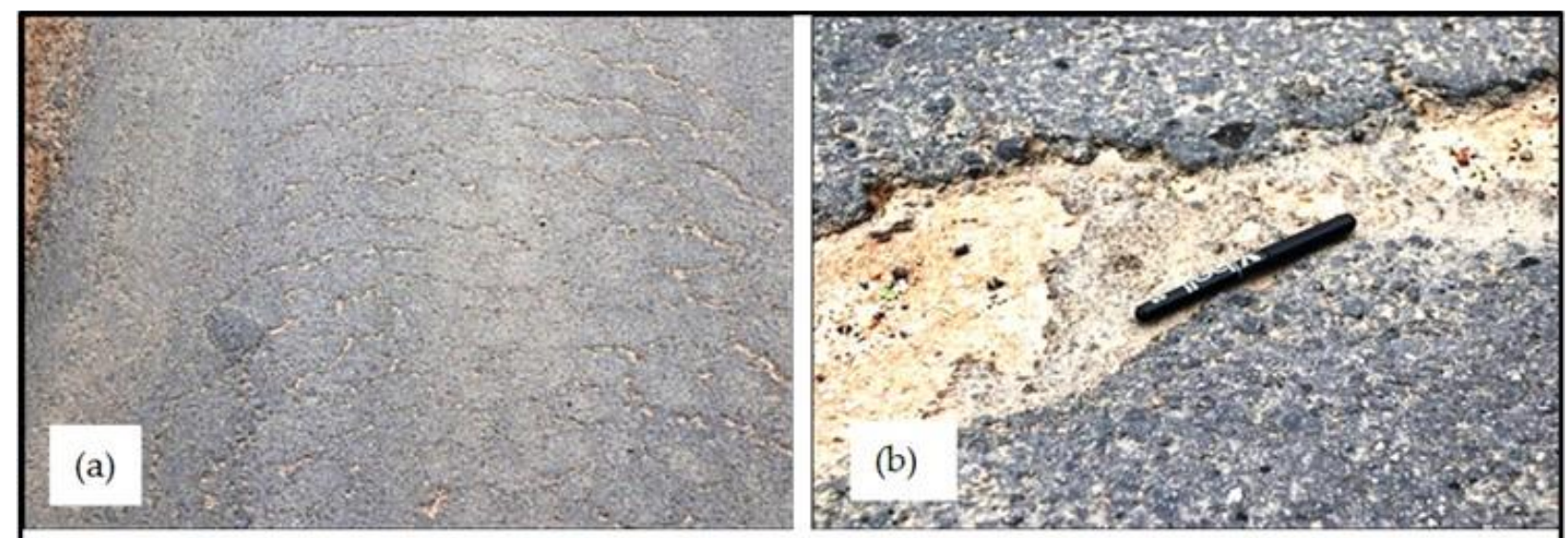

Movement and "bulging" of the asphalt surfacing from the wheel-tracks towards the edge of the road

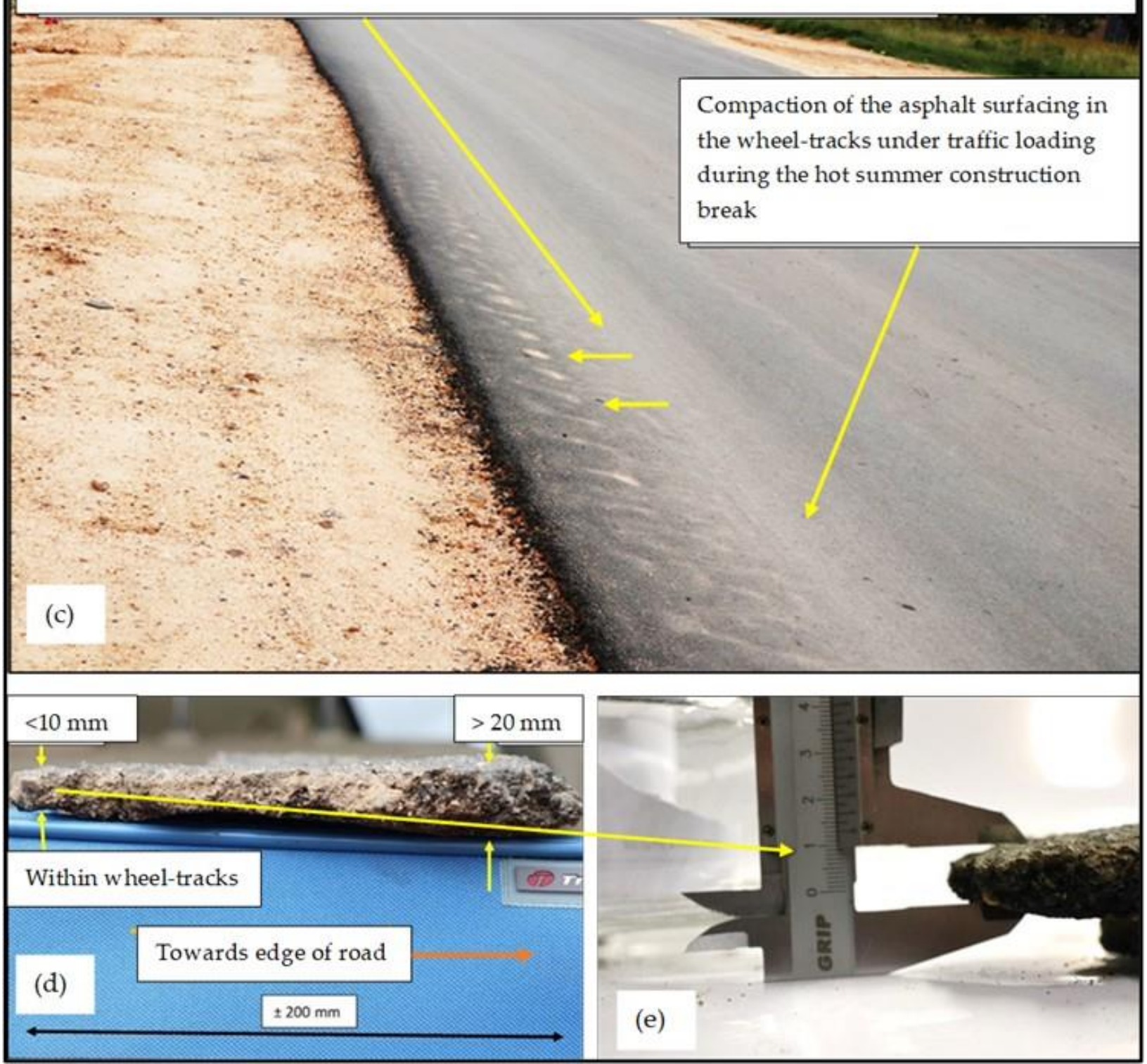

Figure 13: (a) Parabolic cracking indicative of shear; (b) Exposed base layer with prime still sticking to the base-layer; (c) Action resulting in rut-depth measurements in excess of $50 \mathrm{~mm}$; (d and e) Surfacing taken from road shows a thickness within the wheel-tracks of less than $10 \mathrm{~mm}$ thickening towards the edge of the road where the thickness exceeded $60 \mathrm{~mm}$.

From the Forensic Investigation it was established that, in a haste to finish the section of road before the summer break, the surfacing was placed in rain (specifically prohibited 
under the project specifications) and compacted under those conditions The placement of the surfacing in the rain (without supervision) created a slip-plane and little adhesion to the base-layer. The average compaction measured after construction showed an average compaction density of only 91.5 per cent compared to the specification of a minimum of 93 per cent. Under the action of traffic, in the hot summer days during the construction break, the asphalt compacted and moved sideways towards the edge of the road as shown in Figure 13. The thickness of asphalt examples taken from site indicated a thickness of less than $10 \mathrm{~mm}$ in the wheel-tracks, resulting into a thickness of more than $60 \mathrm{~mm}$ towards the edge of the road. The result is a rut depth of more than $50 \mathrm{~mm}$ within the wheel-tracks.

The distress, shown and discussed in this example, could easily have been prevented if sound construction practices have been followed. However, the example demonstrates the "first line of attack" that will be used with the introduction of new technologies. It also demonstrates the importance of experienced designers, with the required practical experience, to be available to construction supervision personnel to give expert advice and the required support to resolve construction problems.

\subsection{Incompatibility of materials}

A problem generally applicable to pavement engineering is the use of incompatible materials together in the same design. These incompatibilities are not normally addressed in design documents and is a major problem associated with the general use of catalogue designs in combination with documents addressing available stabilising and binder modifications without emphasizing the basic principle of material compatibility. A first rule of thumb borrowed from basic chemistry is "likes prefer likes", i.e. similar binders prefer and works well with the same type of binder. Figure 14 shows the application of two binders on the same anionic NME stabilised sample. On the left, a similar NME modified binder was used in the placement of the chip-seal. The seal could not be separated from the sample with a trowel resulting in the breaking of the stone chips without separating the applied chip seal. The binder of the chip-seal on the right contained a latex modified binder which showed little adhesion to the anionic NME stabilised sample. In fact the seal on the sample on the right could easily be removed by hand.

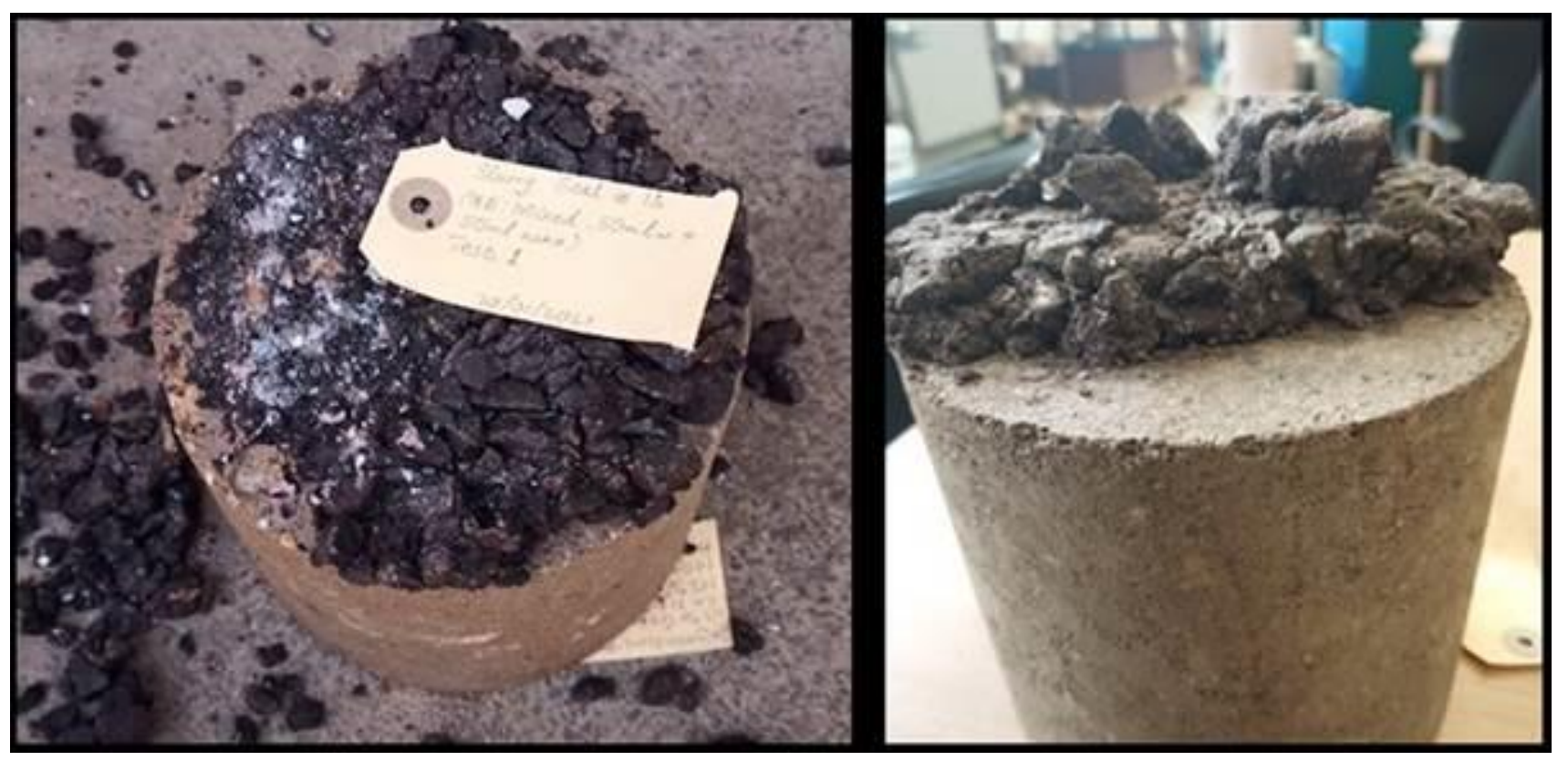

Figure 14: Application of different binders to the same NME stabilised samples showing the results of the use of compatible (left) and incompatible binders (right

Similar to Figure 14, the differences in the application of an applicable prime are shown in Figure 15. On the left (a) is the application of a diluted anionic NME prime applied to the surfacing of an anionic NME stabilised sample. On the right (b) is the 
consequences of the application of a diluted cationic prime to an anionic stabilised base layer, resulting in little (or no) adhesion and catastrophic failures.

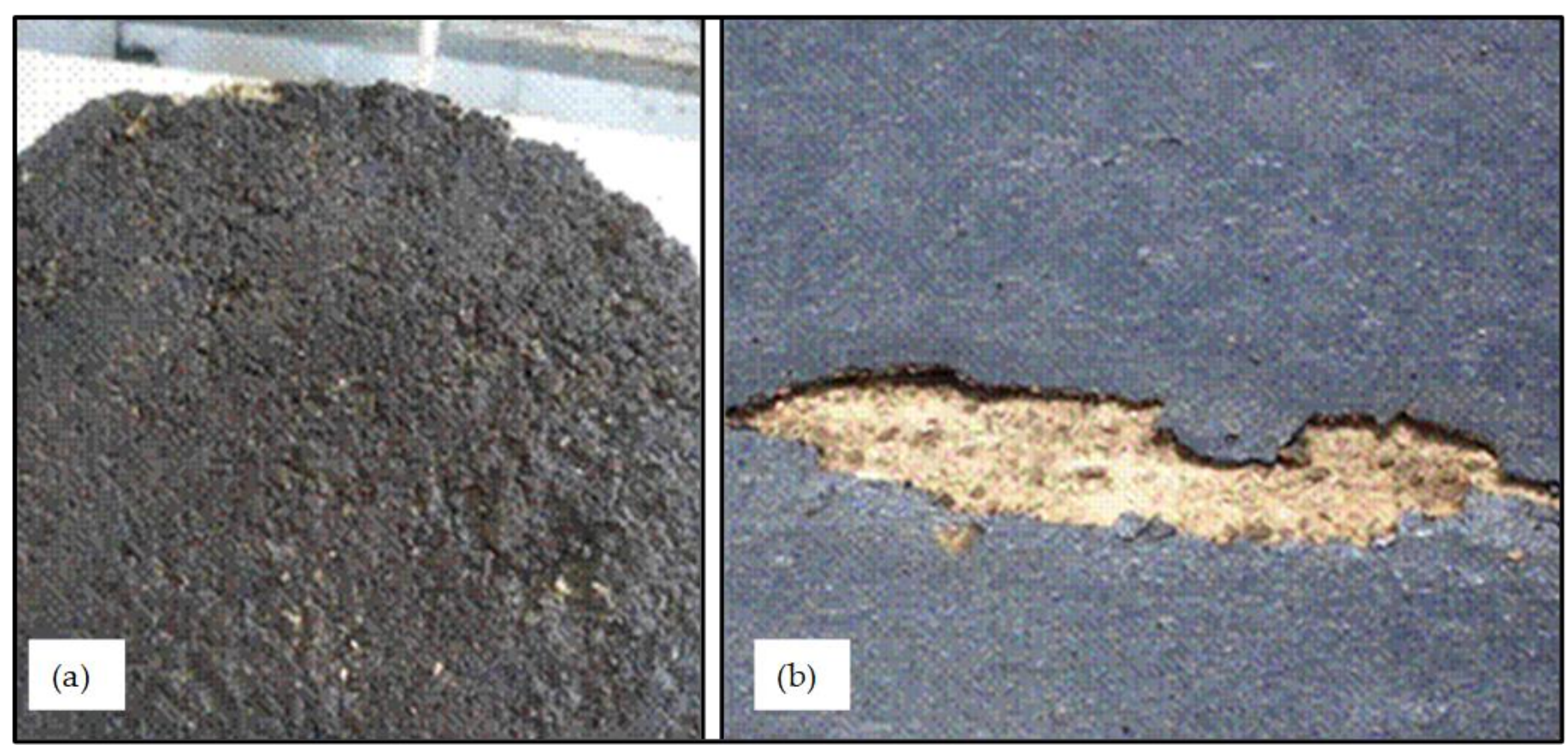

Figure 15: Material compatible prime of an anionic stabilised sample (left) (a), versus a non-compatible prime applied to an anionic stabilised base layer (right) (b).

Any selection of a modified binder also needs to be compatible with the future expected performance of a pavement structure. A pavement structure normally requires in the order of two seasons to reach an equilibrium moisture condition. It follows that any surfacing selected must provide for the pavement structure to expel excess moisture in the form of vapour, independent of the type of modification (or not) used in the construction of the base layer. Unfortunately, many of the newly introduced modifications to bituminous binders "inhibits" the escape of moisture. Industry documents, often includes warnings as to disadvantages of the use of specific modifications to bituminous materials. However, in practice these warnings are often not taken notice off, with designers only focussing on the possible advantages.

The use of a modified binder on a newly constructed road could have severe repercussions, in the form of:

- Collection of moisture underneath the surfacing resulting in stripping or detachment of the surfacing from the base, especially in the use of a thin chip-seal (Figure 16(a), or

- Collection of moisture underneath the surfacing in the top of the base layer, resulting in the punching of chips into the base (in the case of a chip-seal) with severe bleeding and resultant failure (Figure 16(b and c)). 


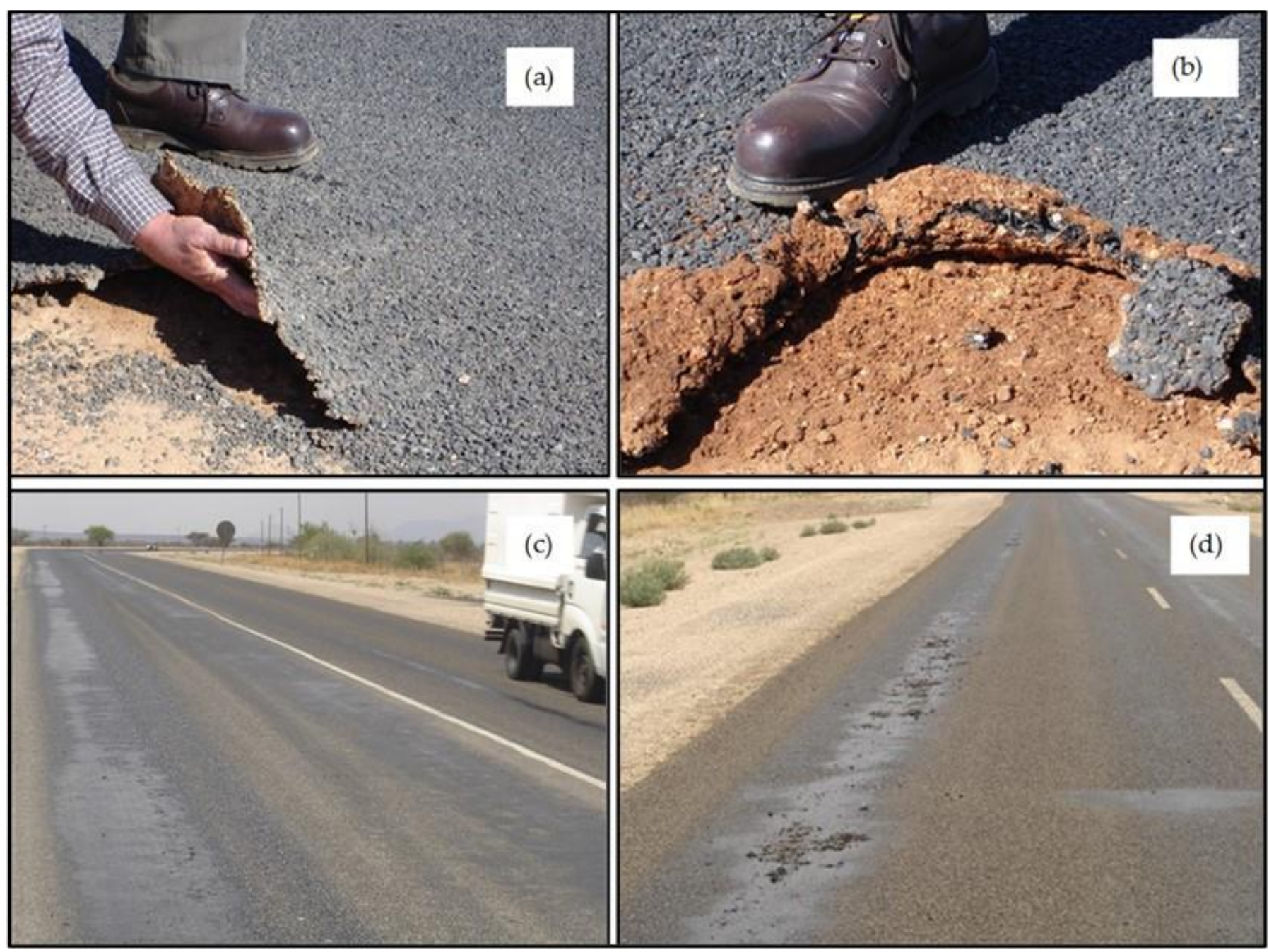

Figure 16: (a) Detachment of the surfacing from the base-layer; (b) Collection of moisture collecting under a surfacing that inhibits the escape of moisture fumes leading to the conditions shown in (a), (b) and (c); (c) Punching of the surfacing into the base-layer; (d) Failure resulting from the punching of the surfacing into the base-layer.

7.6 Addressing and assuring the depth of stabilisation during the rehabilitation of roads utilising in-situ materials

Many pre-mature failures have been investigated and could directly be associated with the depth of reworking and in-situ stabilisation not meeting the specified depths. Modern recyclers are easily programmed to change the depth of reworking which could result in considerable savings both in time and costs of the application of the stabilising agent. Without permanent supervisory staff monitoring every detail, these changes are sometimes difficult to detect. As a consequence, to counter these activities, it is often specified that pavement layers identified to be reworked and stabilised be pre-milled and windrowed to the specified depth. A new road-bed will then be recompacted before the milled material is reintroduced and stabilised. Using this approach, the designed layer thicknesses are ensured, enabling careful monitoring and quality control as a preventative measure to limit pre-mature failures in a quest for sustainable designs. Figure 17 show the milling and windrowing of pavement layers before reintroduction and in-situ stabilisation using an anionic NME stabilising agent.

Modern construction equipment is able to easily rework layer up to a depth of at least $450 \mathrm{~mm}$ and successfully compact layers of these thicknesses to the specified densities. Before allowing contractors to deviate from the original design by combining layers, these practices should be verified with the design engineer. 


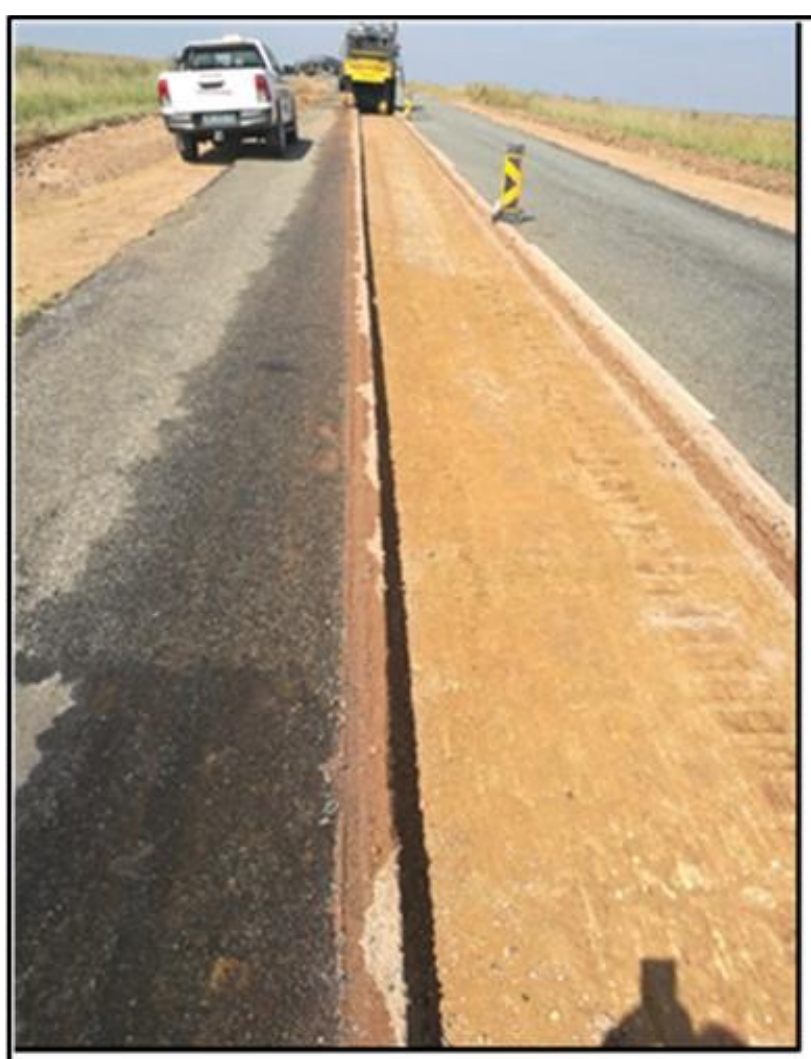

(a)

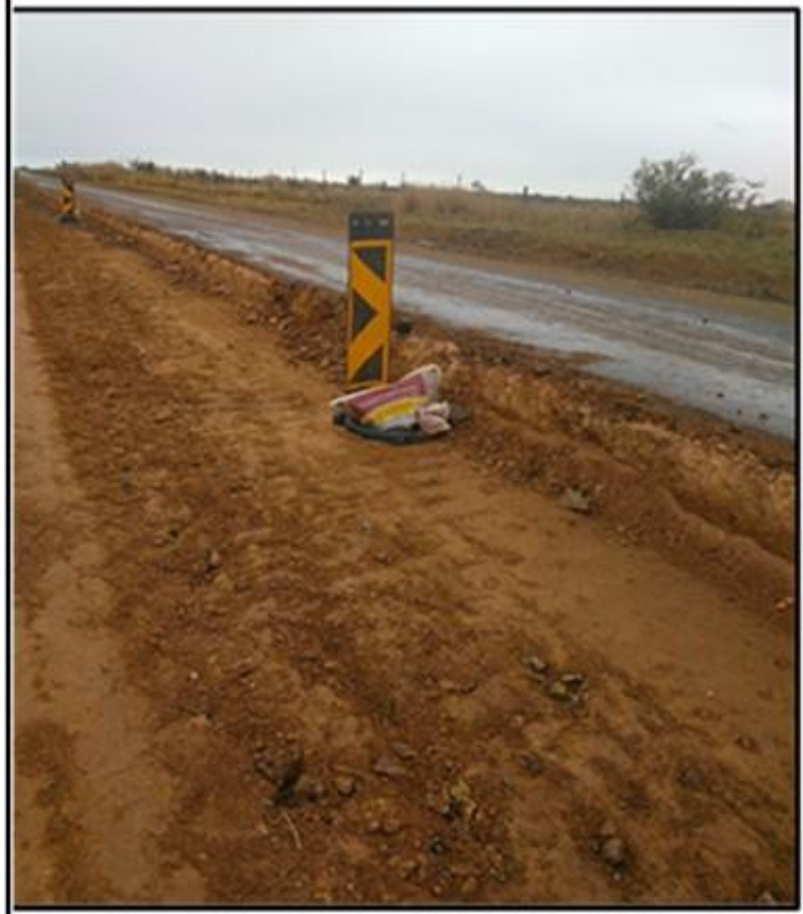

(c)

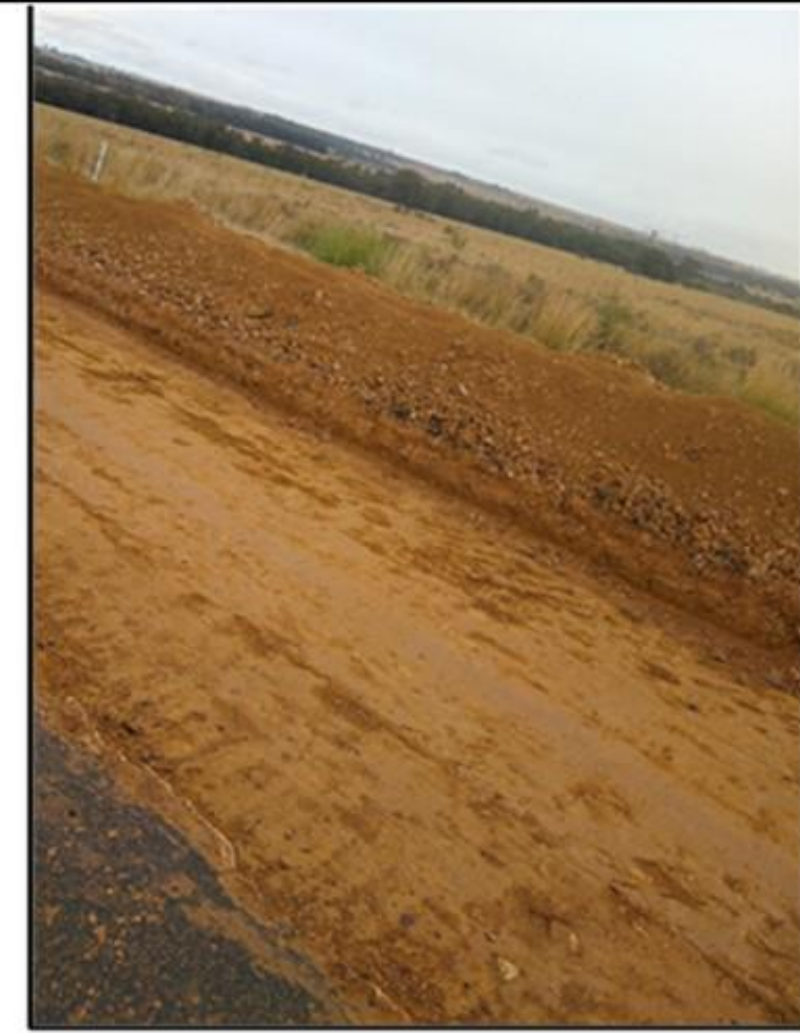

(b)

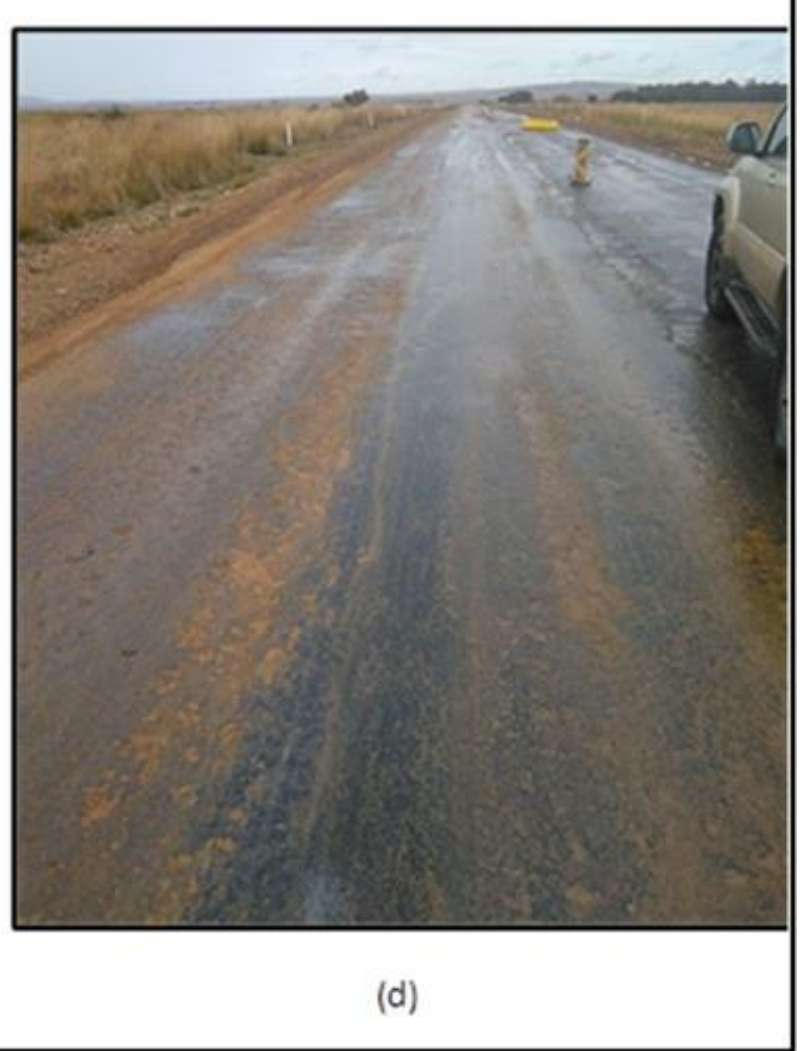

Figure 17: (a) Milling of existing base and sub-base layers to be stabilised using an anionic NME stabilising agent; (b) Stockpiling of material next to the road; (c) Showing depth of milling and new road-bed to be compacted, and (d) Showing the reintroduced sub-base and base separately stabilised using an anionic stabilising agent

The reason for this is simple. The stress/strain distribution of a pavement structure containing, for example, two $150 \mathrm{~mm}$ stabilised layers may not necessarily be the same as 
the stress/strain distribution of a single $300 \mathrm{~mm}$ stabilised layer. It follows, that the combination of layers within a pavement structure may have an influence on the bearing capacity of the pavement structure. This example is especially relevant for the stabilisation of layers creating a semi-ridged structure with a low tolerance toward flexure (tensile) strength. Pavement engineering has experienced a strong movement away from empirically based design methods towards Mechanistic-Empirical (ME) design methods. ME design methods enables a detailed analysis of stress/strain distributions through complex pavement structures. These abilities and associated proven failure theories, should be fully utilised by design engineers to approve or disapprove any deviation of the specified design as requested by a contractor. Decisions should not be based solely on the ability of the equipment to perform certain actions and on-site personnel not familiar with the original design approach used.

\section{Conclusions}

Granular materials traditionally classified as marginal in terms of use for the construction of roads various (as a function of a specific road category), stabilised and improved by using material compatible nanotechnologies in the form of New-age (Nano) Modified Emulsions (NME),have been tested and evaluated over a number of years in laboratories, through Accelerated Pavement Tests (ATP) and in practice. Scientifically based material design methods, based on the mineralogy of the granular materials, have been developed to ensure that potential risks associated with the introduction of these new technologies are minimised, if not eliminated. From all the evidence produced, there is little doubt that the introduction of the NME nanotechnology products can contribute considerably towards the construction of roads at a considerably reduced unit costs. The implementation of these available and proven technologies can contribute significantly towards the cost-effective delivery of sustainable, much needed road infrastructure without compromising the quality of the end product. In-fact, from the available results, it is evident that the durability of the roads will be improved through the use of material compatible nanotechnologies that introduce water-repellent characteristics which inhibits insitu chemical weathering of granular materials.

However, the acceptance and roll-out of new technologies in the provision of bulk infrastructure, need to be accepted by the construction industry. The use of these nanotechnologies has been shown to be construction friendly, applicable to any existing construction method and/or with any available equipment from the most basic to the most advanced. Provided that the recommended materials design method is followed (based on scientific principles of mineralogy and chemistry) and the recommended procurement procedures are followed to ensure that a high-quality material compatible NME stabilising agents are used, it is highly unlikely that the NME stabilising will contribute to construction related problems.

The introduction of any new technologies into the construction industry, makes it an obvious target to blame and a "first line of attack" in the case of any construction problems. This article specifically addresses problems encountered on construction sites where an anionic NME stabilising agent with marginal granular materials have been used in the construction of the base-layer. In all cases discussed, the immediate response was to blame the use of technologies "not proven", relating the use of NME stabilising agents to previous experiences with so called "snake oils". However, in all the examples discussed, all problems were related to either procedural, poor supervision or equipment related aspects.

The examples discussed in this article aims to counter any uninformed opinions by identifying the real cause and mechanism of distress where the natural reaction was to immediately blame the introduction of nanotechnology modifications to the stabilising agent. Actual projects covered, using granular materials previously considered as of unacceptable quality, includes roads varying from highways to the upgrade of local access roads and the in-situ rehabilitation of rural and urban streets. Experienced has shown that 
construction related problems can be prevented and or rectified by following basic sound construction procedures applicable to the use of any material, including the:

- Use of construction water of a quality as specified;

- Cleaning of equipment as specified - NME stabilising agents are reactive in nature and will react with any residue left in water-bowsers, etc. from previous projects resulting in unusable "blobs" or " strings" of bituminous material;

- Maintaining of equipment to ensure that equipment related problems are not the prevailing reason for construction related problems (most problems encountered could directly be related to problems with the equipment and a general lack of good maintenance policies), and

- Provide supervisory site personnel (foremen) with adequate experience to timeously identify problems to enable and rectify these problems cost-effectively.

In summary, the NME stabilisation of granular materials for the construction of roads have been shown to be forgiving and to be:

- Construction friendly;

- Equipment tolerant, and

- Cost-effective.

Author Contributions: G.J.J. under the directive of the Head of Department of Civil Engineering, W.J.vdM.S., has been leading the research into the provision of affordable road infrastructure at the faculty of Engineering, University of Pretoria. He has been instrumental in the design, implementation and construction supervision of roads using nanotechnologies. W.J.vdM.S. recognized the potential of nanotechnology solution in the field of pavement engineering more than a decade ago. G.J.J., through involvement in the private sector, has been responsible for the development of scientific principles, ensuring that implementation can be achieved at a minimum risk. All authors have read and agreed to the published version of the manuscript.

Funding: This research received no external funding.

Institutional Review Board Statement: Not applicable.

Informed Consent Statement: Not applicable.

Data Availability Statement: Not applicable.

Acknowledgments: The support of GeoNANO Technologies (Pty) Ltd., 18 Davies road, Wychwood, Germiston, 1401, South Africa, Tel: +27844078489, www.geonano.co.za, info@geonano.co.za, in support of students in the Department of Civil Engineering, University of Pretoria, Pretoria, South Africa, to test a wide variety of materials as part of final year projects and post-graduate theses, testing the various principles identified in this paper, is acknowledged.

Conflicts of Interest: The authors declare no conflict of interest.

\section{References}

1. Von Ebelman, J.J. Untersuchungen über die Verbinddungender Borsäure mit Aetther. Ann. Chem. Pharm. 1846, 57, 319-353.

2. Von Hoffman, W. Stone-preserving processes: Royal Institute of British Architects. Build. 1861, 19, $103-105$.

3. Wheeler, G. Alkoxysilanes and the Consolidation of Stone; The Getty Conservation Institute: Los Angeles, CA, USA, 2005.

4. Zhang, S. Material Characterisation Techniques; CRC Press: Boca Raton, FL, USA, 2008; ISBN 1420042947.

5. Steyn, W.J.vdM. Potential Applications of Nanotechnology in Pavement Engineering. J. Transp. Eng. $2009,135,764-772$.

6. Porto, M.; Caputo, P.; Eskandarsefat, S.; Teltayev, B.; Rossi, C.O.. Bitumen and Bitumen Modification: A review on Latest Advances. Appl. Sci. 2019, 02, 742. https://doi.org/10.3390/app9040742.

7. Caputo, P., Porto, M., Angelico, R., Loise, V., Calandra, P. and Rossi, C.O.. Bitumen and asphalt modified nanometre-sized particles: Basic concepts, the state of the art and future perspectives of the nanoscale approach. Journal in Advances in Colloid and Interface Science 285 (2020) 102283, 2020. https://doi.org/10.1016/j.cis.2020.102283

8. Jordaan, G.J.; Steyn, W.J.vdM. A Comprehensive guide to the Use of Applicable and Proven Nano-Technologies in the Field of Road Pavement Engineering Design and Construction; Department of Civil Engineering, University of Pretoria: Pretoria, South Africa, 2019; ISBN 978-0-620-83022-5.

9. Southern Africa Transport and Communications Commission (SATCC). Guideline: Low-Volume Sealed Roads; Published by the Southern Africa Development Community (SADC), SADC House, Gaborone, Botswana: 2003; ISBN 99912-0-456-5.

10. Jordaan, G.J.; Kilian, A. The cost-effective upgrading, preservation and rehabilitation of roads - Optimising the use of available technologies. In Proceedings of the 2016 Southern Africa Transportation Conference (SATC 2016), Pretoria, South Africa, 4-7 July 2016. 
11. National Centre for Asphalt Technology (NCAT). Effects of Nanotac Additive on Bond Strength and Moisture Resistance of Tach Coats; NCAT: Auburn, AL, USA, 2011.

12. Akhalwaya, I.; Rust, C.F. Laboratory evaluation of road construction materials enhanced with nano-modified emulsions (NME). In Proceedings of the Southern African Transportation Conference (SATC'18), Pretoria, South Africa, 9-12 July 2018.

13. Kidgell, M.M.; Steyn, W.J.vdM.; Jordaan, G.J. Effect of Nano-Modified Emulsions (NME) (nano-silanes) stabilisers on the properties of Dolomite, Proceedings of the 2019 Southern African Transportation Conference (SATC'19), Pretoria, South Africa, 2019.

14. Rust, F.C.; Akhalwaya, I.; Jordaan, G.J.; Du Plessis, L. Evaluation of a nano-silane-modified emulsion stabilised base and subbase under HVS traffic. In Proceedings of the 12th Conference on Asphalt Pavements for Southern Africa (CAPSA 2019), Sun City, South Africa, 13-16 October 2019.

15. Rust, F.C.; Smit, M.A.; Akhalwaya, I.; Jordaan, G.J.; Du Plessis, L. Evaluation of two nano-silane-modified emulsion stabilised pavements using accelerated pavement testing. Int. J. Pavement Eng. 2020, doi:10.1080/10298436.2020.1799210.

16. Jordaan, G.J.; Steyn, W.J.; Broekman, A. Evaluation of cost-effective modified binder thin chip and cape seal surfacings on an anionic nano-modified emulsion (NME)-stabilised base layer using accelerated pavement testing (APT). Appl. Sci. 2021, 11, 2514. doi:10.3390/app11062514.

17. Jordaan, G.J.; Kilian, A.; Machiavelli, N.; Dlamini, D. Practical Application of Nano-Technology in Roads in Southern Africa. In Proceedings of the 8th Transportation Technology Transfer (T2) Conference, Lusaka, Zambia, 4-8 March 2017.

18. Jordaan, G.J.; Steyn, W.J.V. Practical Application of Nanotechnology Solutions in Pavement Engineering: Construction Practices Successfully Implemented on Roads (Highways to Local Access Roads) Using Marginal Granular Materials Stabilised with New-Age (Nano) Modified Emulsions (NME). Preprints 2021, 2021100181 (doi: 10.20944/preprints202110.0181.v3).

19. Jordaan, G.J.; Kilian, A.; Du Plessis, L.; Murphy, M. The development of cost-effective pavement design approaches using mineralogy tests with new nano-technology modifications of materials. In Proceedings of the 2017 Southern Africa Transportation Conference (SATC 2017), Pretoria, South Africa, 10-13 July 2017.

20. Jordaan, G.J.; Steyn, W.J.vdM. Testing of granular/soil characteristics for the optimisation of pavement designs using reactive stabilising agents including "new-age" nano-technologies. In Proceedings of the 12th Conference of Asphalt Pavements for Southern Africa (CAPSA 2019), Sun City, South Africa, 13-16 October 2019.

21. Jordaan, G.J.; Steyn, W.J.vdM. Fundamental principles ensuring successful implementation of new-age (nano) modified emulsions (NME) for the stabilisation of naturally available materials in pavement engineering. Appl. Sci. 2021, 11, 1745. doi:10.3390/app11041745.

22. Jordaan, G.J.; Steyn, W.J.vdM. Engineering Properties of New-Age (Nano) Modified Emulsion (NME) Stabilised Naturally Available Granular Road Pavement Materials Explained Using Basic Chemistry. Appl. Sci. 2021, 11, 9699. https://doi.org/10.3390/app11209699.

23. Jordaan, G.J.; Steyn, W.J.vdM. Nanotechnology Incorporation into Road Pavement Design Based on Scientific Principles of Materials Chemistry and Engineering Physics Using New-Age (Nano) Modified Emulsion (NME) Stabilisation/Enhancement of Granular Materials. Appl. Sci. 2021, 11, 8525. https://doi.org/10.3390/app11188525.

24. Steyn, W.J.vdM.; The upside of disruptive 4IR technology and innovation, University World News - Africa Edition, 2021.

25. South African National Standards (SANS). SANS 3001: Civil Engineering Test Methods - GR53: Determination of the Unconfined Compressive Strength of Compacted and Cured Specimens of Cementitiously Stabilised; SABS Standards Division: Pretoria, South Africa, 2010.

26. South African National Standards (SANS). SANS 3001: Civil Engineering Test Methods - GR54: Determination of the Indirect Tensile Strength of Compacted and Cured Specimens of Cementitiously Stabilised Materials; SABS Standards Division: Pretoria, South Africa, 2010.

27. Committee of Land Transport Officials (COLTO), Draft TRH4: Structural Design of Flexible Pavements for Interurban and Rural Roads; National Institute for Transport and Road Research (NITRR), CSIR: Pretoria, South Africa, 1996.

28. Jordaan, G.J. Optimisation of Flexible Road Pavement Rehabilitation Investigations and Design; Department of Civil Engineering, University of Pretoria: Pretoria, South Africa, 2013., Distributed through www.lulu.com, ISBN 978-1-77592-036-6.

29. Jordaan, G.J.; Steyn, W.J. Cost-Effective Upgrading of Gravel Roads Using Naturally Available Materials with New-Age Modified Emulsion (NME) Stabilisation; Department of Civil Engineering, University of Pretoria: Pretoria, South Africa, 2020; ISBN 978-0-62091415-4.

30. The South African Institute of Civil Engineers, General Conditions of Contract for Construction Works, Published by the South African Institute of Civil Engineers, Third Edition, Midrand, South Africa, 2015.

31. Jordaan, G.J.; Van As, C.S. Pavement evaluation: Test frequency requirements for deflection parameters. Proceedings of the $6^{\text {th }}$ Conference of Asphalt Pavements for Southern Africa (CAPSA), Cape Town, 1994. 